\title{
Inhaled Nitric Oxide Preserves Ventricular Function During Resuscitation Using a Percutaneous Mechanical Circulatory Support Device in a Porcine Cardiac Arrest Model - An Echocardiographic Myocardial Work Analysis
}

Christoph Nix

Abiomed Europe $\mathrm{GmbH}$

Rashad Zayat ( $\nabla$ r.zayat@gmail.com )

Universitätsklinikum Aachen: Universitatsklinikum Aachen https://orcid.org/0000-0003-2243-8743

Andreas Ebeling

RWTH University Hospital: RWTH University Aachen Faculty of Medicine

Andreas Goetzenich

Abiomed Europe $\mathrm{GmbH}$

Uma Chandrasekaran

AbioMed Inc

Rolf Rossaint

RWTH University Hospital: RWTH Aachen University Faculty of Medicine

Nima Hatam

RWTH University Hospital: RWTH Aachen University Faculty of Medicine

Matthias Derwall

RWTH University Hospital:RWTH Aachen University Faculty of Medicine

\section{Research}

Keywords: Left ventricular assist device, Percutaneous mechanical circulatory support, Cardiac arrest, Cardiopulmonary resuscitation, Left ventricular unloading, Nitric oxide, Impella

Posted Date: December 1st, 2020

DOI: https://doi.org/10.21203/rs.3.rs-115076/v1

License: (1) (i) This work is licensed under a Creative Commons Attribution 4.0 International License.

Read Full License 


\section{Abstract}

\section{Background}

Resuscitation using a percutaneous mechanical circulatory support device (iCPR) improves survival after cardiac arrest (CA). We hypothesized that the addition of inhaled nitric oxide (iNO) during iCPR might prove synergistic, leading to improved myocardial performance due to lowering of right ventricular (RV) afterload, left ventricular (LV) preload, and myocardial energetics. This study aimed to characterize the changes in LV and RV function and global myocardial work indices (GWI) following iCPR, both with and without iNO, using 2-D transesophageal echocardiography (TEE) and GWI evaluation as a novel noninvasive measurement.

Methods

In 10 pigs, iCPR was initiated following electrically-induced CA and 10min of untreated ventricular fibrillation (VF). Pigs were randomized to either 20ppm (20ppm, n=5) or Oppm $(0 p p m, n=5)$ of iNO in addition to therapeutic hypothermia for $5 \mathrm{~h}$ following ROSC. All animals received TEE at five pre-specified time-points and invasive hemodynamic monitoring.

Results

LV end-diastolic volume (LVEDV) increased significantly in both groups following CA. iCPR alone led to significant LV unloading at $5 \mathrm{~h}$ post-ROSC with LVEDV values reaching baseline values in both groups (20ppm: $68.2 \pm 2.7$ vs. $70.8 \pm 6.1 \mathrm{~mL}, \mathrm{p}=0.486 ; 0 p p m: 70.8 \pm 1.3$ vs. $72.3 \pm 4.2 \mathrm{~mL}, \mathrm{p}=0.813$, respectively). LV global longitudinal strain (GLS) increased in both groups following CA. LV-GLS recovered significantly better in the 20ppm group at 5 h post-ROSC (20ppm: $-18 \pm 3 \%$ vs. Oppm: $-13 \pm 2 \%, p=0.025)$. LV-GWI decreased in both groups after CA with no difference between the groups. Within Oppm group, LV-GWI decreased significantly at $5 \mathrm{~h}$ post-ROSC compared to baseline $(1,125 \pm 214$ vs. $1,835 \pm 305 \mathrm{mmHg} \%$, $\mathrm{p}=0.011)$. RV-GWI was higher in the 20ppm group at $3 \mathrm{~h}$ and 5 h post-ROSC (20ppm: $189 \pm 43 \mathrm{vs.} \mathrm{Oppm:}$ $108 \pm 22 \mathrm{mmHg} \%, \mathrm{p}=0.049$ and $20 \mathrm{ppm}$ : $261 \pm 54$ vs. $0 p p m: 152 \pm 42 \mathrm{mmHg} \%, \mathrm{p}=0.041$ ). The blood flow calculated by the Impella controller following iCPR initiation correlated well with the pulsed-wave Doppler (PWD) derived pulmonary flow (PWD vs. controller: $1.8 \pm 0.2$ vs. $1.9 \pm 0.2 \mathrm{~L} / \mathrm{min}, r=0.85, \mathrm{p}=0.012$ ).

\section{Conclusions}

iCPR after CA provided sufficient unloading and preservation of the LV systolic function by improving LVGWI recovery. The addition of iNO to iCPR enabled better preservation of the RV-function as determined by better RV-GWI. Additionally, Impella-derived flow provided an accurate measure of total flow during iCPR.

\section{Background}


Cardiac arrest (CA) remains associated with high mortality and poor functional outcome. Despite the growing clinical use of mechanical circulatory support (MCS) for cardio-pulmonary resuscitation (CPR) after $\mathrm{CA}$, the contribution towards a higher survival rate and the better functional outcome is yet to be demonstrated. An animal study showed a beneficial effect of the early use of a percutaneous mechanical circulatory support device, termed intravascular CPR (iCPR), on post-CPR survival [1]. An additional inhaled nitric oxide (iNO) application in an animal model resulted in improved trans-pulmonary blood flow and was associated with improved neurological outcomes [2]. We hypothesized that the synergistic effects of iNO during iCPR were a result of improved myocardial performance due to lowering of right ventricular (RV) afterload, left ventricular (LV) preload, and myocardial energetics. Previous studies have demonstrated a cardio-protective effect of ventricular unloading by percutaneous MCS through reduction in myocardial wall stress and myocardial work (MW) [3]. Recently, echocardiographic MW assessment has emerged as a non-invasive method to evaluate myocardial performance and gain more insights into myocardial energetics and mechanics, given the strong correlation with invasive pressure-volume (PV) measurements [4].

Thus, in the present study, we aimed to better understand the effect of iNO during iCPR on the myocardial performance and mechanics in a well-established large animal model of CA [1, 2]. The left (LV) and right ventricular (RV) function before, during, and after iCPR were analyzed using 2-D transesophageal echocardiography (TEE), deformation imaging, tissue Doppler (TDI) and non-invasive myocardial work measurement. In addition, trans-pulmonary flow (TPF) inferred by pulsed-wave Doppler (PWD) during iCPR was compared to the calculated pump flow derived from the Impella controller.

\section{Methods}

The experimental protocol was approved by the appropriate governmental institution (Landesamt für Natur, Umwelt und Verbraucherschutz NRW (LANUV), Recklinghausen, Germany) and has been previously described [1, 2]. All animals received adequate care according to the precepts of the Helsinki declaration. Ten healthy female swine (Deutsche Landrasse, Sus scrofa domesticus), approximately four months of age, and weighing 44 to $57 \mathrm{~kg}$ were used in this study. All pigs had a clinical examination on arrival at the facility. Animals were housed in pens with a $12 \mathrm{~h}$-day-night cycle and access to drinking water ad libitum. Twelve hours before the experiment, the pigs were set on nil per os except for drinking water access.

\section{Animal instrumentation}

Figure 1 provides and overview of animal instrumentation and the experiment model. The pigs were weighed before the start of the experiment. General anesthesia was induced by intramuscular injection of $4 \mathrm{mg} / \mathrm{kg}$ azaperone (Stresnil, Janssen-Cilag $\mathrm{GmbH}$, Neuss, Germany), followed by intravenous injection of $15 \mathrm{mg} / \mathrm{kg}$ sodium pentobarbital (Nacoren, Boehringer Ingelheim Vetmedica $\mathrm{GmbH}$, Ingelheim am Rhein, Germany). Anesthesia was maintained by continuous intravenous sodium pentobarbital infusion at a rate of $4 \mathrm{mg} / \mathrm{kg} / \mathrm{h}$. The pigs were placed in a supine position, intubated orotracheally, and the legs were fixed in an extended position. Animals were ventilated with an inspired oxygen fraction of 0.3 (Servo 
Ventilator 300A; Siemens AG, Munich, Germany). Tidal volume was set to $10 \mathrm{ml} / \mathrm{kg}$, and respiratory rate was adjusted to keep the end-tidal carbon dioxide partial pressure within a physiologic range $(35 \pm 4$ $\mathrm{mmHg}$ ). A continuous five lead electrocardiogram (ECG) and pulse oximetry were performed. Convective air heating was used to maintain body temperature at $38 \pm 0.5^{\circ} \mathrm{C}$ during preparation (Warm Touch 5200 ; Tyco Healthcare, Pleasanton, CA, USA).

\section{Hemodynamic monitoring}

Arterial blood pressure was obtained using a fluid-filled catheter (Vygon, Ecquen, France) placed into the left femoral artery. For pulmonary artery pressure and cardiac output measurements, a Swan-Ganz catheter (744HF75; Edwards Lifesciences, Irvine, CA, USA) was flow-directed into the pulmonary artery and connected to a cardiac output monitor (Vigilance; Edward Lifesciences). Impella flow was taken from the motor current based flow calculation on the AIC (Automated Impella Controller) as described in detail earlier [5].

\section{Cardiac arrest model}

As described previously [1, 2], cardiac arrest was induced using an alternating current of 1 to $2 \mathrm{~mA}$ delivered to the endocardium of the right ventricle, resulting in VF. Simultaneously, mechanical ventilation was discontinued.

A 13-French sheath introducer (Impella 2.5 introducer kit 13 F, $13 \mathrm{~cm}$; Abiomed Europe GmbH, Aachen, Germany) was placed in the right femoral artery. A modified Impella 2.5 left ventricular assist device (Abiomed) equipped with a shortened angled cannula to meet the anatomical constraints of the animal was introduced using the vascular access into the left ventricle with the help of fluoroscopy guidance, pigtail catheter (Cordis 6 F PIG $145^{\circ} 110 \mathrm{~cm}$ Super Torque Plus; Cordis, Miami Lakes, FL, USA) and a guidewire (Platinum Plus 0.018 in $\times 260 \mathrm{~cm}$; Boston Scientific, Natick, MA, USA) (see Figure 1 for details).

Impella 2.5 support was activated at the maximum achievable flow ten minutes following the onset of VF. The pig was then randomized (closed envelope method) to a $\mathrm{FiO}_{2}$ of 1.0 without any added iNO (group Oppm; $\mathrm{n}=5$ ) versus a $\mathrm{FiO}_{2}$ of 1.0 blended with 20ppm of inhaled nitric oxide (group 20ppm; $\mathrm{n}=5$ ). Therapeutic mild hypothermia was induced using $0.5 \mathrm{~L}$ of a $6^{\circ} \mathrm{C}$ cold Ringer's solution and topical application of ice bags to the groins in all animals. The blood temperature was maintained at $33 \pm 1^{\circ} \mathrm{C}$. A continuous infusion of Ringer's solution was administered at $4 \mathrm{ml} / \mathrm{kg} / \mathrm{h}$ to ensure adequate hydration.

\section{Transesophageal Echocardiography}

All TEE studies were performed by the same board-certified physician at baseline (after all catheters were placed), during VF and iCPR, and at 30mins, 3h, 5h post-ROSC. We used a commercially available ultrasound machine (Vivid E9, GE Vingmed Ultrasound AS, Horten, Norway) equipped with a 6VT-D [3.08.0MHz] TEE probe. Our detailed TEE protocol in swine has been described previously [6]. In brief, at least three consecutive cardiac cycles were stored and averaged for all measurements. The analysis was 
carried out offline using the device's software package (EchoPAC Version 202; GE Vingmed Ultrasound AS, Horten, Norway) according to the recommendation of the European Association of Cardiovascular imaging [7]. Images were acquired from mid-esophageal, trans-gastric, and upper esophageal views. Valvular pathologies were excluded by color-Doppler. LV end-diastolic (LVEDV) and end-systolic (LVESV) volumes were measured in the mid-esophageal four-chamber $(4-\mathrm{CH})$ views and deep esophageal twochamber (2-CH) views. The modified biplane Simpson's method was used for Ejection fraction (EF) measurements [8]. RV fractional area change (RV-FAC) was determined according to the following formula:

$$
\mathrm{RV}-\mathrm{FAC}=\frac{\text { end-diastolic area }- \text { end-systolic area }}{\text { end-diastolic area }} \times 100 \%
$$

TDI was used to measure RV peak systolic tricuspid annulus velocity (TASV) from a 4-CH view as an indicator of RV longitudinal function [9]. The PWD sample was placed in RV- (RVOT) and LV-outflow tracts (LVOT) to obtain velocity time integrals (VTI). RV Cardiac output (CO) was calculated using the formula: $\mathrm{CO}=\mathrm{VTI}_{\mathrm{RVOT}} \times \mathrm{RVOT}$ cross-sectional area $\mathrm{x}$ heart rate and for the $\mathrm{LV} \mathrm{CO}=\mathrm{VTI}_{\mathrm{LVOT}} \mathrm{x}$ LVOT crosssectional area $\mathrm{x}$ heart rate.

\section{Speckle tracking and non-invasive myocardial work measurements:}

2-D speckle-tracking (STE) was used to define LV global longitudinal strain (LV-GLS) and RV-GLS. LV GLS was measured using the three apical chamber views (4-CH, 2-CH and apical long axis (LAX)). For STE analysis of the RV the $4 \mathrm{CH}$ view for the RV anterior wall was used. The RV free wall was captured from a modified upper long axis view (LAX) of the RV in- and outflow tract and part of the posterior RVOT was obtained from a mid-esophageal LAX RV view (Please refer to supplementary figure 1 for a representative view). Aortic and mitral valve opening and closure times were determined by PWD. The systolic arterial and pulmonary blood pressures were entered into the EchoPAC software (GE Vingmed Ultrasound AS, Horten, Norway). After completing the STE analysis of LV and RV, EchoPAC calculated pressure-strain loops (PSL). Adjusted LV pressure curves corresponding to the length of isovolumic and ejection phases were generated by EchoPAC software, as described by Russel et al. [10,11]. The global myocardial work index (GWI) was calculated from the area within the PSL and the following parameters were then calculated from the PSL: 1) GWI: The total myocardial work from mitral valve closure to mitral valve opening is represented by the total area of PSL; 2) global constructive myocardial work (GCW): the ventricular work which contributes to the ejection during systole: GCW = positive work during systole + negative work during isovolumic relaxation; 3) global wasted myocardial work (GWW): the ventricular work that does not contribute to the ejection of blood. GWW = negative work during systole + positive work during isovolumic relaxation; 4) global myocardial work efficiency (GWE): the fraction of constructive myocardial work to total work [10-12]. LV pressure was estimated by adjusting a reference pressure curve with measured blood pressure and with echocardiography derived valvular event timing [10-12]. We used the blood pressure taken from the femoral artery for that purpose. RV's pressure was measured using the Swan-Ganz catheter. The myocardial work was expressed in $\mathrm{mmHg} \%$. EchoPAC 
provided a validated assessment of LV myocardial work indices. To our knowledge, measurements for RV myocardial work indices with EchoPAC were not validated by GE healthcare or by any other research group yet.

\section{Statistical analysis}

Statistical analysis was performed with STATA IC16 (StataCorp., TX, USA) and Jamovi project (Version 1.6.1, https://www.jamovi.org). Figures were created using Graph Pad Prism version 7.0a for MAC OS X (Graph Pad Software, La Jolla, California USA) and prepared for submission using Adobe $\AA^{\text {Illustrator }}{ }^{\circledR}$ CS6 (Adobe Inc., San Jose, California, USA). The normal distribution of continuous variables was assessed using the Shapiro-Wilk-Test, and was expressed as mean \pm standard deviation. A mixed-effects model was used for between-group comparisons at different time-points and Sidak's test was used to account for multiple comparisons. The non-parametric Friedman-test and Dunn's correction for multiple comparisons was used for intergroup comparisons at different time points. Pearson's correlation test was performed to assess the correlation between the invasive thermodilution measured $\mathrm{CO}\left(\mathrm{CO}_{\mathrm{TD}}\right)$ and the PWD derived $\mathrm{CO}\left(\mathrm{CO}_{\mathrm{PWD}}\right)$. Adjusted $\mathrm{p}$-values for multiple comparisons are presented and $\mathrm{p}<0.05$ was considered statistically significant.

\section{Results}

\section{Impella controller derived flow correlates well with pulsed-wave Doppler derived flow}

All 10 pigs survived $15 \mathrm{~h}$ post-ROSC and were successfully extubated. No complications due to TEE probe insertion or during TEE image acquisition were observed. Body surface area was similar between groups (Oppm: $1.2 \pm 0.1$ vs. $20 p p m: 1.3 \pm 0.1 \mathrm{~m}^{2}, \mathrm{p}=0.278$ ). At least two different clear views of $4-\mathrm{CH}, 2-\mathrm{CH}$, and $\mathrm{LAX}$ at all given time points were obtained in all animals.

The mean heart rate at baseline was $92 \pm 14 \mathrm{~min}^{-1}$. The systemic and pulmonary artery pressure at baseline did not differ between groups and are presented in Table 1. $\mathrm{CO}_{\mathrm{PWD}}$ correlated well with the invasively measured $\mathrm{CO}_{\mathrm{TD}}$ at baseline, 30min, 3h and $5 \mathrm{~h}(r=0.71, \mathrm{p}=0.021 ; r=0.91, \mathrm{p}<0.001 ; r=0.93$, $p<0.001 ; r=0.84, p<0.01$, respectively) (Figure 2 ). The calculated pump flow displayed by the automated Impella controller correlated well with the PWD derived pulmonary flow following iCPR initiation $(1.8 \pm 0.2$ vs. $1.9 \pm 0.2 \mathrm{~L} / \mathrm{min}, r=0.85, \mathrm{p}=0.012$ ).

\section{Application of iNO significantly increases cardiac output and improves left ventricular systolic function recovery}

At baseline, LVEDV, LV-EF and LV-GLS did not differ between groups. After induction of VF, LVEDV increased significantly in both groups compared to baseline (Figure 3A). Over the course of iCPR for 5 hours, LVEDV decreased and returned closer to baseline values in both groups (Figure 3A and Table 2). However, LVEDV in the 20ppm group was higher at all time points and was statistically significant at $3 \mathrm{~h}$ post-ROSC (Oppm: $78.2 \pm 1.1$ vs. $20 p p m: 70.8 \pm 1.3 \mathrm{~mL}, \mathrm{p}<0.001$ ). LV-EF did not differ significantly between 
groups at all time points or within each group compared to baseline (Figure 3B). The LV-GLS improved throughout the duration of iCPR in both groups from baseline (Figure $3 \mathrm{C}$ ). The LV-GLS values were significantly lower at $3 \mathrm{~h}$ and $5 \mathrm{~h}$ post-ROSC in the 20ppm group compared to the Oppm group (5h: Oppm: $-13.1 \pm 2.4$ vs. $20 p p m:-18.2 \pm 3.4, p=0.025$ ) (Figure $3 C$ ). The $C O$ decreased in both groups at iCPR initiation and improved over the course of iCPR. The $\mathrm{CO}_{\mathrm{PWD}}$ increased significantly in the 20ppm group at $3 \mathrm{~h}$ and 5h post-ROSC compared to the Oppm group (3h: Oppm: $4.6 \pm 0.9 \mathrm{~L} / \mathrm{min}$ vs. $20 p p m: 6.6 \pm 1.1, \mathrm{p}=0.016$; $5 \mathrm{~h}$ : Oppm: $4.0 \pm 0.6 \mathrm{~L} / \mathrm{min}$ vs. 20ppm: $5.8 \pm 1.0, \mathrm{p}=0.036$ ) (Figure 3D).

\section{Application of iNO enhances right ventricular systolic function recovery}

RV echocardiographic measurements, RV basal diameters at end-diastole (RVEDD), RV-FAC, TASV and RV-GLS, did not differ between the two groups at baseline (Figure 4A-D and Table 2). However, RV-FAC decreased significantly during CA and 30min post-ROSC. In the Oppm group, RV-FAC was lower at all time-points compared to baseline (0ppm baseline vs. $30 \mathrm{~min}$, vs. $3 \mathrm{~h}$ vs. $5 \mathrm{~h}$ post-ROSC: $44.1 \pm 6.1 \%$ vs. $27.4 \pm 2.8 \%, p=0.004$; vs. $32 \pm 5 \%, p=0.009$; vs. $33.2 \pm 4.3 \%, p=0.001$; see also table 2 ). In the $20 p p m$ group, RV-FAC improved at $3 \mathrm{~h}$ and recovered to baseline values at $5 \mathrm{~h}$ post-ROSC (baseline: $42.9 \pm 6.6 \%$ vs. $5 \mathrm{~h}$ : 41.1 $\pm 6.4 ; p=0.442$ ) (Figure 4A). RVEDD increased significantly in both groups at iCPR initiation, and slowly recovered over time but did not differ between groups (Figure 4B and Table 2). Within the Oppm group, TASV decreased significantly after CA and remained lower during the course of iCPR (baseline vs. 3h: $13.6 \pm 1.1$ vs. $7.8 \pm 1.6 \mathrm{~cm} / \mathrm{s}, \mathrm{p}=0.024$; baseline vs. $5 \mathrm{~h}: 13.6 \pm 1.1$ vs. $9.4 \pm 1.3 \mathrm{~cm} / \mathrm{s}, \mathrm{p}=0.009$, respectively) (Figure 4A and Table 2). The TASV values in the 20ppm group were higher at $3 \mathrm{~h}$ and $5 \mathrm{~h}$ post-ROSC compared to the Oppm group (20ppm vs. Oppm at $3 \mathrm{~h}: 11.4 \pm 1.1$ vs. $7.8 \pm 1.6 \mathrm{~cm} / \mathrm{s}, \mathrm{p}=0.024$; at $5 \mathrm{~h}$ : $12.8 \pm 1.1$ vs. $9.4 \pm 1.3 \mathrm{~cm} / \mathrm{s}, p=0.012$ ). The RV-GLS values were similar between the two groups at baseline and post-ROSC. However, RV-GLS at $5 \mathrm{~h}$ post-ROSC was significantly lower in the 20ppm group than Oppm (Oppm vs. $20 p p m$ at $5 \mathrm{~h}:-9 \pm 1.4 \%$ vs. $-13 \pm 2.2 \%$; $p=0.007$; Figure $4 \mathrm{D})$.

\section{LV myocardial work indices indicate recovery during and after ventricular unloading}

At baseline, myocardial work indices (GWI, GWE, GCW, GWW) did not differ between the two groups (Figure 5A-D and Table 2). The LV-GWI did not differ between the two groups at any time. However, LVGWI in the 20ppm group recovered after an initial decrease and began to recover at 30min post-ROSC to reach almost baseline values at $5 \mathrm{~h}$ post-ROSC (baseline: $1,751 \pm 270 \mathrm{mmHg} \%$ vs. $5 \mathrm{~h}: 1,529 \pm 274 \mathrm{mmHg} \%$, $\mathrm{p}=0.401$ ) (Figure $5 \mathrm{~A}$ and Table 2), while in the Oppm group, LV-GWI was significantly lower compared to baseline at all time-points (baseline: $1,835 \pm 305 \mathrm{mmHg} \%$; $30 \mathrm{~min}: 891.2 \pm 412 \mathrm{mmHg} \%(p=0.032), 3 \mathrm{~h}$ : $896 \pm 129 \mathrm{mmHg} \%(p=0.011)$, and $5 \mathrm{~h}: 1,125 \pm 214 \mathrm{mmHg} \%(p=0.011)$; Figure $5 \mathrm{~A})$. LV-GWE and LV-GCW had a similar time-course to LV-GWI and did not recover in the Oppm group (Figure 5B). The LV-GWW did not differ between groups and did not increase significantly in both groups at all time-points compared to baseline (Figure 5C).

$R V$ myocardial indices indicate a more complex pattern and slower recovery 
At baseline, the RV myocardial work indices did not differ between groups (Oppm vs. 20ppm, Figure 6A-C and Table 2). At $3 \mathrm{~h}$ and $5 \mathrm{~h}$ post-ROSC, RV-GWI was significantly lower in the Oppm group compared to the $20 p p m$ group (Oppm: $108.4 \pm 22.6$ vs. $20 p p m: 189.6 \pm 43.6 \mathrm{mmHg} \%, \mathrm{p}=0.049$ and $0 p p m: 152.6 \pm 42.4$ vs. $261.6 \pm 54.2 \mathrm{mmHg} \%, \mathrm{p}=0.041$, respectively). Within the Oppm group, the RV-GWI did not recover and remained significantly decreased at $30 \mathrm{~min}, 3 \mathrm{~h}$ and $5 \mathrm{~h}$ post-ROSC compared to baseline (baseline: $338.2 \pm 45.3 \mathrm{mmHg} \%$ vs. $30 \mathrm{~min}: 101.6 \pm 34.5 \mathrm{mmHg} \%, p<0.001$; vs. $3 \mathrm{~h}: 108.4 \pm 22.6 \mathrm{mmHg} \%, p<0.001$; vs. $5 \mathrm{~h}: 152.6 \pm 42.4 \mathrm{mmHg} \%, \mathrm{p}=0.012$, respectively; Figure $6 \mathrm{~B}$ ). In both groups, the RV-GCW decreased significantly after $\mathrm{CA}$, but a slow recovery over time was noted in both groups with no difference between groups (Figure 6B and Table 2). The RV-GWW increased significantly in the Oppm group compared to the $20 \mathrm{ppm}$ group at $3 \mathrm{~h}$ and $5 \mathrm{~h}$ post-ROSC: $69.6 \pm 11.9$ vs. $47.4 \pm 6.7, \mathrm{p}=0.049$ and $77.8 \pm 14.8$ vs. $50.2 \pm 8.2$, $\mathrm{p}=0.046$, respectively (Figure $6 \mathrm{C}$ ). The RV-GWE increased significantly in the $20 \mathrm{ppm}$ group at $5 \mathrm{~h}$ postROSC compared to the Oppm group ( $80 \pm 5.2$ vs. $73 \pm 5.7, p=0.042$, respectively)

\section{Diagnostic utilization of pressure-strain loops}

Figure 7A is a representative overlay of the PS-loops of the LV. An acute injury following iCPR initiation is demonstrated by narrowing of the PS-loop (a sign of loss in maximally generated strain), thus explaining the ventricle's inability to generate sufficient pressure [13-17].

The partially positive strain indicates a passive distention of the myocardium due to volume loading [1517]. Unloading leads to slow recovery and progressive normalization of the PS-loop, which remains below (i.e., less negative) normal values but shows a curve pattern comparable to normal conditions $[17,18]$.

Figure 7B is a representative overlay of the PS-loops of the right ventricle. A pumping failure leads to increased RVP, and a loss in strain translates to a more complex strain-pressure relation $[19,20]$. The RV strain reduction remains pronounced even after a longer duration of left ventricular support $[20,21]$.

Figure 7C demonstrates the spatial distribution of strain at different time-points. This allows differentiation of regional wall motion deterioration e.g., in acute myocardial infarction from global failure, thus providing a detailed perspective on myocardial recovery over time.

\section{Discussion}

Resuscitation following cardiac arrest remains associated with significant mortality and morbidity [22]. Although treatment guidelines recommend inotropes and vasopressors, many studies have demonstrated their detrimental side effects [22]. In the early phase of resuscitation, treatments aim to augment or stabilize cardiac output, allowing minimal end-organ perfusion, and reducing or preventing hypoxic/ischemic injury [12-14]. However, these treatments cause increased myocardial stress and oxygen demand when oxygen supply is low $[23,24]$.

Trans-valvular mechanical support devices like the Impella device family uncouple the myocardial workload from the systemic cardiac output (which is then primarily provided by the pump), leading to 
adequate end-organ perfusion while resting the heart [3, 25]. Previous studies [26-28] have demonstrated the efficacy of this intravascular resuscitation, and the present study in an animal model confirms the results and provides additional insights on the temporal evolution of the effect.

\section{Global myocardial work and the principle of unloading}

The pressure-strain (PS) loop generated by tracking the global myocardial strain vs. the LVEDP/RVEDP over the cardiac cycle provides a momentary impression of the myocardial work and is comparable to the pressure-volume (PV) loops derived from conductance catheters $[4,10,11]$. Russel et al. [10,11] demonstrated a strong correlation between the non-invasive LV PS-loop area and the invasive PV-loop area. The LV PV-loop analysis considers the LV load and has been shown in experimental studies to be a reliable and robust method for quantifying LV performance. Moreover, the PV-loop area provides valuable information on the myocardial $\mathrm{O}_{2}$-consumption $[29,30]$. Despite being a valuable and reliable method, the PV-loop method is not used in clinical practice due to its invasiveness $[10,11,31,32]$.

Evaluation of ventricular function is an essential component of all echocardiographic examinations. Despite the many LVEF measurement limitations, LVEF remains the most widely used parameter for systolic function evaluation [33]. More recently, the peak longitudinal strain from 2D-speckle tracking analysis has gained acceptance in the clinical routine. Compared to EF, GLS can detect subclinical myocardial abnormalities. However, GLS analysis suffers from load dependency and has limitations [34].

The PS-loop analysis incorporates both the deformation changes and afterload, thus overcoming the limitations of load dependency [4]. Therefore, GWI provides incremental information to EF and GLS analysis. While the PV-loop area reflects myocardial metabolic demand and oxygen consumption, the non-invasive myocardial work method provides myocardial energetics [10, 11,32]. For several decades, stroke work evaluation played a key role in heart failure characterization and decision-making regarding optimal treatment. Traditional stroke work measurements are calculated using the LV PV-loop area derived from invasive catheterization [29,30]. The PS-loop method has a robust correlation with invasive PV-loops and enables evaluating myocardial wasted work and work efficiency [11]. The value and clinical implications of non-invasively estimated myocardial work indices have been tested in several clinical entities. Recently, Galli et al. [35] demonstrated the value of GWW and GWI in providing details on dyssynchronous contraction and segmental work. The authors [35] identified, that responders to cardiac resynchronization therapy have a higher GCW than non-responders. Using GWI and GWW enabled the early identification of patients with acute coronary occlusion with non-ST-elevation [4]. Ischemia induces changes in myocardial contraction, and it has been shown that patients with subclinical ischemia have a dyssynchronous contraction and increased GWW [14].

Secondary right ventricular failure can aggravate cardiogenic shock [36, 37]. Thus, prevention of right ventricular distension might play a crucial role in limiting progression to right ventricular failure, even during intravascular resuscitation [37]. Notably, the right ventricular preload is increased during left ventricular mechanical support [38]. Transvalvular LV pumps depend on left ventricular preload to prevent 
suction and allow for optimal flows [38, 39]. Reduction in right ventricular afterload by pulmonary vasodilatation, leading to a decrease in pulmonary vascular resistance, should facilitate the reduction of left ventricular filling and right ventricular myocardial workload $[40,41]$. The results of this study confirmed that iNO successfully decreases right ventricular afterload, normalizes RV filling pressure over time, and shifts the RV strain towards a normal (i.e., baseline) configuration.

\section{Limitations}

The small sample size of the study limits the significance of our analysis as it was not adequately powered for multiple comparisons. However, from an ethical perspective, the downsizing of experimental groups is part of the $3 R$ strategy. The TEE measurements in swine are challenging due to specific anatomic features. Special attention was paid to avoid foreshortening of the left ventricle in echocardiography, and ante- and retroflexion of the tip was used to correctly identify the apex of the heart. Despite all the precautions, foreshortened ventricle views might have underestimated the left ventricular volumes including the stroke volume, $R V D_{3}$ and $R V$ areas. $3 D-T E E$ is believed to overcome these limitations and would have led to a more precise calculation of the derived parameters. The image quality of two-chamber-views can be limited due to swine anatomy (the bronchus partially conceals the heart from the esophagus). There are no studies comparing RV PS-loops with invasive PV-loops, to the best of our knowledge, due to lack of specific software for RV myocardial work assessment. We used the commercially available LV software provided by GE for RV myocardial work measurements. Therefore, the results must be interpreted with caution. The peripheral arterial pressure was used for PS-loop evaluation, which might be lower than the central arterial due to a lack of pressure augmentation.

\section{Conclusions}

During resuscitation from cardiac arrest, iCPR provides sufficient unloading and preservation of endorgan perfusion by maintaining cardiac output and improving myocardial work recovery. The addition of inhaled nitric oxide enables improved preservation of RV function as determined by better recovery of RV global work indices. Myocardial work estimation by echocardiographic analysis can help understand and guide both left and right ventricular unloading to minimize myocardial stress and oxygen demand, while maintaining sufficient end-organ perfusion.

\section{Abbreviations}

CA: Cardiac arrest

$\mathrm{CO}_{\mathrm{PWD}}$ : Cardiac output as measured by pulsed-wave Doppler

$\mathrm{CO}_{\mathrm{TD}}$ : Cardiac output measured with thermodilution method using Swan-Ganz catheter

DBP: Diastolic blood pressure 
DPAP: Diastolic pulmonary artery pressure

GCW: Global constructed myocardial work

GLS: Global longitudinal strain

GWE: Global myocardial work efficiency

GWI: Global myocardial work index;

GWW: Global wasted work

HR: Heart rate

$\mathrm{HR}_{p p-V F} \mathrm{~min}^{-1}$ : peak to peak inspiration frequency as the heart rate during cardiac arrest

iCPR: Percutaneous mechanical cardiopulmonary resuscitation

iNO: Inhaled nitric oxide

LAX: apical long axes view

LV: Left ventricle

LVEDV: Left ventricular end-diastolic volume

LVEF: Left ventricular ejection fraction

LVEDP: Left ventricular diastolic pressure

LVOT: Left ventricular outflow tracts

PSL: Pressure strain loop

PV-loop: Pressure-volume loop

PWD: Pulsed-wave Doppler

ROSC: Return of spontaneous circulation

RV: Right ventricle

RVEDD: Right ventricular end-diastolic diameter

RVEDP: Right ventricular diastolic pressure

RVD1: Right ventricle basal diameter 
RVD2: mid right ventricle diameter

RV3: Iongitudinal right ventricle diameter

RV-FAC: Right ventricular fractional area change

RVOT: Right ventricular outflow tracts

SBP: Systolic blood pressure

SPAP: Systolic pulmonary artery pressure

STE: 2-D speckle-tracking echocardiography

TASV: Tricuspid annular systolic velocity

TDI: Tissue Doppler imaging

TEE: Transesophageal echocardiography

VTI: Velocity time integrals

\section{Declarations}

Ethics approval and consent to participate: The experimental protocol was approved by the appropriate governmental institution (Landesamt für Natur, Umwelt und Verbraucherschutz NRW (LANUV), Recklinghausen, Germany) Az.: 84-02.04.2017.A300

Consent for publication: Not applicable

Availability of data and materials: The datasets used or analyzed during the current study are available from the corresponding author on reasonable request.

Competing interests: $\mathrm{AG}$ and $\mathrm{CN}$ are full-time employee of Abiomed Europe $\mathrm{GmbH}$, Germany. UM is a fulltime employee Inc., USA. All other authors declare no competing interests

Funding: This work was supported by the German Research Foundation (Deutsche Forschungsgemeinschaft, DFG) [Grant Number DE 1685/3-1]. MD received unrestricted educational research grants and travel allowances from Abiomed Europe. The sponsor was not involved in study design; in the collection, analysis and interpretation of data; in the writing of the report; and in the decision to submit the article for publication.

\section{Authors' contributions:}

CN wrote and drafted the manuscript 
$\mathrm{CN}, \mathrm{MD}, \mathrm{NH}, \mathrm{RR}$ conception and Study design

$C N, A E, A G, M D, R Z$ carried out the experiments, participated in the data acquisition

$\mathrm{RZ}, \mathrm{NH}$ performed and analyzed the echocardiographic studies

$\mathrm{CN}, \mathrm{AE}, \mathrm{NH}, \mathrm{RZ}$ collected and analyzed the data

$A G, M D, N H, R R, U M$ Interpretation of the analysis

All authors critically revised the manuscript for important intellectual content

All authors have approved the submitted version

Acknowledgements not applicable

Authors' information not applicable

\section{References}

1. Derwall M, Brücken A, Bleilevens C, Ebeling A, Föhr P, Rossaint R, Kern KB, Nix C, Fries M: Doubling survival and improving clinical outcomes using a left ventricular assist device instead of chest compressions for resuscitation after prolonged cardiac arrest: a large animal study. Crit Care 2015, 19(1):123.

2. Derwall M, Ebeling A, Nolte KW, Weis J, Rossaint R, Ichinose F, Nix C, Fries M, Brücken A: Inhaled nitric oxide improves transpulmonary blood flow and clinical outcomes after prolonged cardiac arrest: a large animal study. Crit Care 2015, 19(1):328.

3. Curran J, Burkhoff D, Kloner RA: Beyond Reperfusion: Acute Ventricular Unloading and Cardioprotection During Myocardial Infarction. J Cardiovasc Transl Res 2019, 12(2):95-106.

4. Boe E, Russell K, Eek C, Eriksen M, Remme EW, Smiseth OA, Skulstad H: Non-invasive myocardial work index identifies acute coronary occlusion in patients with non-ST-segment elevation-acute coronary syndrome. European heart journal cardiovascular Imaging 2015, 16(11):1247-1255.

5. Al-Rashid F, Nix C, Erbel R, Kahlert P: Tools \& Techniques - clinical: percutaneous catheter-based left ventricular support using the Impella CP. Eurolntervention 2015, 10(10):1247-1249.

6. Billig S, Zayat R, Ebeling A, Steffen H, Nix C, Hatam N, Schnöring H, Derwall M: Transesophageal echocardiography in swine: evaluation of left and right ventricular structure, function and myocardial work. The international journal of cardiovascular imaging 2020.

7. Flachskampf FA, Wouters PF, Edvardsen T, Evangelista A, Habib G, Hoffman P, Hoffmann R, Lancellotti P, Pepi M: Recommendations for transoesophageal echocardiography: EACVI update 2014. European heart journal cardiovascular Imaging 2014, 15(4):353-365.

8. Lang RM, Badano LP, Mor-Avi V, Afilalo J, Armstrong A, Ernande L, Flachskampf FA, Foster E, Goldstein SA, Kuznetsova T et al: Recommendations for cardiac chamber quantification by 
echocardiography in adults: an update from the American Society of Echocardiography and the European Association of Cardiovascular Imaging. J Am Soc Echocardiogr 2015, 28(1):1-39 e14.

9. Rudski LG, Lai WW, Afilalo J, Hua L, Handschumacher MD, Chandrasekaran K, Solomon SD, Louie EK, Schiller NB: Guidelines for the echocardiographic assessment of the right heart in adults: a report from the American Society of Echocardiography endorsed by the European Association of Echocardiography, a registered branch of the European Society of Cardiology, and the Canadian Society of Echocardiography. J Am Soc Echocardiogr 2010, 23(7):685-713; quiz 786-688.

10. Russell K, Eriksen M, Aaberge L, Wilhelmsen N, Skulstad H, Gjesdal O, Edvardsen T, Smiseth OA: Assessment of wasted myocardial work: a novel method to quantify energy loss due to uncoordinated left ventricular contractions. Am J Physiol Heart Circ Physiol 2013, 305(7):H996-1003.

11. Russell K, Eriksen M, Aaberge L, Wilhelmsen N, Skulstad H, Remme EW, Haugaa KH, Opdahl A, Fjeld $J G, G j e s d a l ~ O$ et al: A novel clinical method for quantification of regional left ventricular pressurestrain loop area: a non-invasive index of myocardial work. Eur Heart J 2012, 33(6):724-733.

12. Hubert A, Le Rolle V, Leclercq C, Galli E, Samset E, Casset C, Mabo P, Hernandez A, Donal E: Estimation of myocardial work from pressure-strain loops analysis: an experimental evaluation. European heart journal cardiovascular Imaging 2018, 19(12):1372-1379.

13. Previtero M, Azzolina D, Palermo C, Tenaglia RM, Sammarco G, Ruozi N, Aruta P, lliceto S, Muraru D, Badano L: ROLE OF NON-INVASIVE LEFT VENTRICULAR PRESSURE-STRAIN LOOP TO PREDICT CARDIAC DEATH AND ARRHYTHMIC RISK IN PATIENT WITH ORGANIC HEART DISEASE AND REDUCED LEFT VENTRICULAR EJECTION FRACTION. Journal of the American College of Cardiology 2019, 73(9 Supplement 1):1625.

14. Lustosa RP, van der Bijl P, El Mahdiui M, Montero-Cabezas JM, Kostyukevich MV, Ajmone Marsan N, Bax JJ, Delgado V: Noninvasive Myocardial Work Indices 3 Months after ST-Segment Elevation Myocardial Infarction: Prevalence and Characteristics of Patients with Postinfarction Cardiac Remodeling. J Am Soc Echocardiogr 2020.

15. Haugaa KH, Grenne BL, Eek CH, Ersbøll M, Valeur N, Svendsen JH, Florian A, Sjøli B, Brunvand H, $\mathrm{K} \emptyset$ ber $\mathrm{L}$ et al: Strain echocardiography improves risk prediction of ventricular arrhythmias after myocardial infarction. JACC Cardiovascular imaging 2013, 6(8):841-850.

16. Zhao H, Lee AP, Li Z, Qiao Z, Fan Y, An D, Xu J, Pu J, Shen X, Ge H et al: Impact of Intramyocardial Hemorrhage and Microvascular Obstruction on Cardiac Mechanics in Reperfusion Injury: A SpeckleTracking Echocardiographic Study. J Am Soc Echocardiogr 2016, 29(10):973-982.

17. Hammoudi N, Watanabe S, Bikou O, Ceccaldi A, Fish K, Yamada KP, Miyashita S, Lebreton G, Hajjar RJ, Ishikawa K: Speckle-Tracking Echocardiographic Strain Analysis Reliably Estimates Degree of Acute LV Unloading During Mechanical LV Support by Impella. J Cardiovasc Trans/ Res 2019, 12(2):135-141.

18. Hedwig F, Soltani S, Stein J, Schoenrath F, Potapov E, Knosalla C, Falk V, Knebel F, Knierim J: Global work index correlates with established prognostic parameters of heart failure. Echocardiography (Mount Kisco, NY) 2020, 37(3):412-420. 
19. Vonk-Noordegraaf A, Westerhof N: Describing right ventricular function. European Respiratory Journal 2013, 41(6):1419-1423.

20. Houard L, Benaets MB, de Meester de Ravenstein C, Rousseau MF, Ahn SA, Amzulescu MS, Roy C, Slimani A, Vancraeynest D, Pasquet A et al: Additional Prognostic Value of 2D Right Ventricular Speckle-Tracking Strain for Prediction of Survival in Heart Failure and Reduced Ejection Fraction: A Comparative Study With Cardiac Magnetic Resonance. JACC Cardiovascular imaging 2019, 12(12):2373-2385.

21. Lejeune S, Roy C, Ciocea V, Slimani A, de Meester C, Amzulescu M, Pasquet A, Vancraeynest D, Beauloye C, Vanoverschelde JL et al: Right Ventricular Global Longitudinal Strain and Outcomes in Heart Failure with Preserved Ejection Fraction. J Am Soc Echocardiogr 2020, 33(8):973-984.e972.

22. Perkins GD, Olasveengen TM, Maconochie I, Soar J, Wyllie J, Greif R, Lockey A, Semeraro F, Van de Voorde P, Lott C et al: European Resuscitation Council Guidelines for Resuscitation: 2017 update. Resuscitation 2018, 123:43-50.

23. BERGLUND E, MONROE RG, SCHREINER GL: Myocardial Oxygen Consumption and Coronary Blood Flow during Potassium-Induced Cardiac Arrest and during Ventricular Fibrillation1. Acta Physiologica Scandinavica 1957, 41(2-3):261-268.

24. Sandroni C, Cavallaro F, Antonelli M: Is there still a place for vasopressors in the treatment of cardiac arrest? Crit Care 2012, 16(2):213.

25. Kapur NK, Reyelt L, Swain L, Esposito M, Qiao X, Annamalai S, Meyns B, Smalling R: Mechanical Left Ventricular Unloading to Reduce Infarct Size During Acute Myocardial Infarction: Insight from Preclinical and Clinical Studies. J Cardiovasc Trans/ Res 2019, 12(2):87-94.

26. Kapur NK, Paruchuri V, Urbano-Morales JA, Mackey EE, Daly GH, Qiao X, Pandian N, Perides G, Karas $\mathrm{RH}$ : Mechanically Unloading the Left Ventricle Before Coronary Reperfusion Reduces Left Ventricular Wall Stress and Myocardial Infarct Size. Circulation 2013, 128(4):328-336.

27. Saku K, Kakino T, Arimura T, Sakamoto T, Nishikawa T, Sakamoto K, Ikeda M, Kishi T, Ide T, Sunagawa K: Total Mechanical Unloading Minimizes Metabolic Demand of Left Ventricle and Dramatically Reduces Infarct Size in Myocardial Infarction. PloS one 2016, 11(4):e0152911.

28. Saku K, Kakino T, Arimura T, Sunagawa G, Nishikawa T, Sakamoto T, Kishi T, Tsutsui H, Sunagawa K: Left Ventricular Mechanical Unloading by Total Support of Impella in Myocardial Infarction Reduces Infarct Size, Preserves Left Ventricular Function, and Prevents Subsequent Heart Failure in Dogs. Circulation Heart failure 2018, 11(5):e004397.

29. Suga H: Ventricular energetics. Physiol Rev 1990, 70(2):247-277.

30. Suga $\mathrm{H}$ : Total mechanical energy of a ventricle model and cardiac oxygen consumption. The American journal of physiology 1979, 236(3):H498-505.

31. Burkhoff D, Mirsky I, Suga H: Assessment of systolic and diastolic ventricular properties via pressurevolume analysis: a guide for clinical, translational, and basic researchers. Am J Physiol Heart Circ Physiol 2005, 289(2):H501-512. 
32. Bonnet B, Jourdan F, du Cailar G, Fesler P: Noninvasive evaluation of left ventricular elastance according to pressure-volume curves modeling in arterial hypertension. Am J Physiol Heart Circ Physiol 2017, 313(2):H237-h243.

33. Konstam MA, Abboud FM: Ejection Fraction: Misunderstood and Overrated (Changing the Paradigm in Categorizing Heart Failure). Circulation 2017, 135(8):717-719.

34. Mor-Avi V, Lang RM, Badano LP, Belohlavek M, Cardim NM, Derumeaux G, Galderisi M, Marwick T, Nagueh SF, Sengupta PP et al: Current and evolving echocardiographic techniques for the quantitative evaluation of cardiac mechanics: ASE/EAE consensus statement on methodology and indications endorsed by the Japanese Society of Echocardiography. European journal of echocardiography : the journal of the Working Group on Echocardiography of the European Society of Cardiology 2011, 12(3):167-205.

35. Galli E, Leclercq C, Hubert A, Bernard A, Smiseth OA, Mabo P, Samset E, Hernandez A, Donal E: Role of myocardial constructive work in the identification of responders to CRT. European heart journal cardiovascular Imaging 2018, 19(9):1010-1018.

36. Cinotti R, Léopold V, Mebazaa A: A Right Insight in Cardiogenic Shock to Get It Right. J Card Fail 2018, 24(3):157-158.

37. Schoenrath F, Hoch D, Maisano F, Starck CT, Seifert B, Wenger U, Ruschitzka F, Wilhelm MJ: Survival, quality of life and impact of right heart failure in patients with acute cardiogenic shock treated with ECMO. Heart \& lung : the journal of critical care 2016, 45(5):409-415.

38. Kapur NK, Langston P, Esposito ML, Burkhoff D: Abrupt development of a trans-aortic valve gradient in the setting of acute left-sided circulatory support identifies right heart failure in cardiogenic shock: The Kapur-Langston sign. Cardiovasc Revasc Med 2020.

39. Mandawat A, Rao SV: Percutaneous Mechanical Circulatory Support Devices in Cardiogenic Shock. Circ Cardiovasc Interv 2017, 10(5).

40. Kapur NK, Esposito ML, Bader Y, Morine KJ, Kiernan MS, Pham DT, Burkhoff D: Mechanical Circulatory Support Devices for Acute Right Ventricular Failure. Circulation 2017, 136(3):314-326.

41. Zayat R, Ahmad U, Stoppe C, Khattab MA, Arab F, Moza A, Tewarie L, Goetzenich A, Autschbach R, Schnoering H: Sildenafil Reduces the Risk of Thromboembolic Events in HeartMate II Patients with Low-Level Hemolysis and Significantly Improves the Pulmonary Circulation. Int Heart J 2018, 59(6):1227-1236.

\section{Tables}

Table 1. Hemodynamic parameters before, during and after the resuscitation using a percutaneous mechanical circulatory support device. 


\begin{tabular}{|c|c|c|c|c|}
\hline & Oppm & 20ppm & Total & $p$ \\
\hline \multirow[t]{2}{*}{$B S A m^{2}$} & $1.2 \pm 0.1$ & $1.3 \pm 0.1$ & $1.3 \pm 0.1$ & 0.271 \\
\hline & Baseline & & & \\
\hline$H R \min ^{-1}$ & $85.6 \pm 13.9$ & $98.4 \pm 11.6$ & $92.0 \pm 13.8$ & 0.152 \\
\hline$S B P \mathrm{mmHg}$ & $129.2 \pm 16.5$ & $126.4 \pm 20.3$ & $127.8 \pm 17.5$ & 0.817 \\
\hline$D B P \mathrm{mmHg}$ & $68.6 \pm 8.6$ & $67.4 \pm 5.9$ & $68.0 \pm 7.0$ & 0.805 \\
\hline SPAP $\mathrm{mmHg}$ & $26.6 \pm 2.8$ & $24.8 \pm 3.6$ & $25.7 \pm 3.2$ & 0.400 \\
\hline DPAP $\mathrm{mmHg}$ & $14.2 \pm 2.7$ & $12.4 \pm 2.9$ & $13.3 \pm 2.8$ & 0.337 \\
\hline$C O_{P W D} L / \min$ & $6.9 \pm 1.7$ & $7.0 \pm 0.8$ & $7.0 \pm 1.3$ & 0.878 \\
\hline \multirow[t]{2}{*}{$C O_{T D} L / \min$} & $6.7 \pm 1.5$ & $7.3 \pm 0.7$ & $7.0 \pm 1.2$ & 0.459 \\
\hline & Cardiac arrest & & & \\
\hline$C O_{P W D} L / \min$ & $1.7 \pm 0.2$ & $1.8 \pm 0.2$ & $1.8 \pm 0.2$ & 0.341 \\
\hline Impella flow $\mathrm{L} / \mathrm{min}$ & $1.9 \pm 0.3$ & $1.9 \pm 0.2$ & $1.9 \pm 0.2$ & 0.892 \\
\hline \multirow[t]{2}{*}{$\mathrm{HR}_{p p-V F} m \min ^{-1}$} & $20.8 \pm 1.1$ & $21.4 \pm 0.8$ & $21.1 \pm 0.9$ & 0.491 \\
\hline & 30min post-ROSC & & & \\
\hline HR $\min ^{-1}$ & $115 \pm 24.3$ & $130 \pm 30$ & $128 \pm 36$ & 0.055 \\
\hline$S B P \mathrm{mmHg}$ & $95.2 \pm 12.9$ & $95.6 \pm 25.1$ & $95.4 \pm 18.8$ & 0.976 \\
\hline$D B P \mathrm{mmHg}$ & $64.8 \pm 10.6$ & $64.4 \pm 10.9$ & $64.6 \pm 10.1$ & 0.955 \\
\hline SPAP $\mathrm{mmHg}$ & $26.2 \pm 3.8$ & $25.2 \pm 6.2$ & $25.7 \pm 4.9$ & 0.766 \\
\hline DPAP $\mathrm{mm} H \mathrm{~g}$ & $14.4 \pm 3.5$ & $11.8 \pm 5.3$ & $13.1 \pm 4.5$ & 0.388 \\
\hline$C O_{T D} L / \min$ & $5.5 \pm 1.7$ & $5.6 \pm 1.2$ & $5.6 \pm 1.4$ & 0.900 \\
\hline \multirow[t]{2}{*}{$C O_{P W D} L / \min$} & $5.1 \pm 1.1$ & $5.7 \pm 1.2$ & $5.4 \pm 1.1$ & 0.433 \\
\hline & 3h post-ROSC & & & \\
\hline$H R \min ^{-1}$ & $102.8 \pm 13.9$ & $111.6 \pm 21.6$ & $107.2 \pm 17.7$ & 0.466 \\
\hline$S B P \mathrm{mmHg}$ & $99.6 \pm 8.6$ & $114.2 \pm 28.0$ & $106.9 \pm 21.0$ & 0.298 \\
\hline$D B P \mathrm{mmHg}$ & $68.0 \pm 7.3$ & $65.0 \pm 11.7$ & $66.5 \pm 9.3$ & 0.639 \\
\hline SPAP $\mathrm{mmHg}$ & $28.0 \pm 5.5$ & $28.4 \pm 4.6$ & $28.2 \pm 4.8$ & 0.903 \\
\hline
\end{tabular}




\begin{tabular}{|c|c|c|c|c|}
\hline DPAP $\mathrm{mmHg}$ & $15.0 \pm 3.2$ & $14.4 \pm 3.6$ & $14.7 \pm 3.3$ & 0.790 \\
\hline$C O_{P W D} L / m n_{-}$ & $4.6 \pm 1.0$ & $6.6 \pm 1.1$ & $5.7 \pm 1.5$ & 0.016 \\
\hline \multirow[t]{2}{*}{$C O_{T D} L / m i n$} & $5.1 \pm 0.8$ & $6.8 \pm 2.3$ & $5.9 \pm 1.8$ & 0.172 \\
\hline & 5h post-ROS & & & \\
\hline$H R \min ^{-1}$ & $75.0 \pm 11.0$ & $104.8 \pm 19.6$ & $89.9 \pm 21.7$ & 0.018 \\
\hline$S B P \mathrm{mmHg}$ & $110.2 \pm 13.8$ & $113.0 \pm 18.0$ & $111.6 \pm 15.2$ & 0.790 \\
\hline$D B P \mathrm{mmHg}$ & $68.0 \pm 9.8$ & $66.2 \pm 9.0$ & $67.1 \pm 8.9$ & 0.771 \\
\hline SPAP $\mathrm{mmHg}$ & $32.0 \pm 4.4$ & $23.0 \pm 1.0$ & $27.5 \pm 5.6$ & 0.008 \\
\hline DPAP $\mathrm{mm} H \mathrm{~g}$ & $16.2 \pm 3.7$ & $11.8 \pm 1.3$ & $14.0 \pm 3.5$ & 0.037 \\
\hline$C O_{P W D} L / m n_{-}$ & $4.0 \pm 0.6$ & $5.8 \pm 1.0$ & $4.9 \pm 1.2$ & 0.036 \\
\hline$C O_{T D} L / \min$ & $3.5 \pm 0.6$ & $5.6 \pm 1.5$ & $4.5 \pm 1.6$ & 0.021 \\
\hline
\end{tabular}

$\mathrm{CO}_{P W D}$ : Pulsed- wave Doppler derived cardiac output; $\mathrm{CO}_{T D}$ : Cardiac output measured with thermodilution method using wan-Ganz catheter; DBP: Diastolic blood pressure; DPAP: Diastolic pulmonary artery pressure; HR: Heart rate; $H R R_{p p-V F}$ : Peak to peak ventilation frequency as the Heart rate during cardiac arrest; SBP: Systolic blood pressure; SPAP: Systolic pulmonary artery pressure

Table 2: Comparison of echocardiographic parameters between the groups with and without inhaled nitric oxide. 


\begin{tabular}{|c|c|c|c|c|}
\hline & Oppm & 20ppm & Total & $p$ \\
\hline & \multicolumn{4}{|l|}{ Baseline } \\
\hline$R V D 1 \mathrm{~cm}$ & $3.1 \pm 0.4$ & $3.4 \pm 0.4$ & $3.3 \pm 0.4$ & 0.332 \\
\hline$R V D 2 \mathrm{~cm}$ & $2.6 \pm 0.2$ & $2.7 \pm 0.4$ & $2.6 \pm 0.3$ & 0.417 \\
\hline$R V D 3 \mathrm{~cm}$ & $4.0 \pm 0.2$ & $3.8 \pm 0.4$ & $3.9 \pm 0.3$ & 0.424 \\
\hline$R V-F A C \%$ & $44.1 \pm 6.0$ & $42.9 \pm 6.6$ & $43.5 \pm 6.0$ & 0.772 \\
\hline$\angle V E D V m L$ & $70.5 \pm 3.5$ & $70.9 \pm 6.1$ & $70.7 \pm 4.7$ & 0.911 \\
\hline LVESV $m L$ & $31.9 \pm 4.6$ & $33.4 \pm 3.6$ & $32.6 \pm 4.0$ & 0.583 \\
\hline$L V-E F \%$ & $61.5 \pm 5.8$ & $64.7 \pm 9.2$ & $63.1 \pm 7.5$ & 0.525 \\
\hline$\angle V-G L S \%$ & $-21.0 \pm 5.1$ & $-21.6 \pm 3.4$ & $-21.3 \pm 4.1$ & 0.833 \\
\hline$L V-G W I m m H g \%$ & $1835.3 \pm 306.2$ & $1751 \pm 270.2$ & $3444.3 \pm 5242.8$ & 0.336 \\
\hline$\angle V-G C W m m H g \%$ & $2095.8 \pm 527.4$ & $2103.2 \pm 405.8$ & $2099.5 \pm 443.6$ & 0.981 \\
\hline LV-GWW mmHg\% & $368.0 \pm 208.8$ & $352.4 \pm 115.9$ & $360.2 \pm 159.4$ & 0.887 \\
\hline LV-GWE \% & $85.2 \pm 4.7$ & $80.0 \pm 1.4$ & $82.6 \pm 4.2$ & 0.054 \\
\hline TASV $\mathrm{cm} / \mathrm{sec}$. & $13.6 \pm 1.1$ & $13.8 \pm 1.5$ & $13.7 \pm 1.3$ & 0.817 \\
\hline$R V-G L S \%$ & $-16.4 \pm 3.2$ & $-14.4 \pm 1.8$ & $-15.4 \pm 2.7$ & 0.267 \\
\hline$R V-G W I m m H g \%$ & $338.2 \pm 45.3$ & $286.8 \pm 57.5$ & $312.5 \pm 55.8$ & 0.155 \\
\hline RV-GCW mmHg\% & $376.4 \pm 92.6$ & $266.6 \pm 41.1$ & $321.5 \pm 89.0$ & 0.082 \\
\hline$R V-G W W m m H g \%$ & $61.6 \pm 13.8$ & $55.4 \pm 10.6$ & $58.5 \pm 12.1$ & 0.949 \\
\hline \multirow[t]{2}{*}{$R V-G W E \%$} & $79.8 \pm 10.2$ & $80.8 \pm 6.1$ & $80.3 \pm 7.9$ & 0.855 \\
\hline & \multicolumn{4}{|l|}{ Cardiac arrest } \\
\hline$R V D 1 \mathrm{~cm}$ & $4.0 \pm 0.3$ & $4.2 \pm 0.3$ & $4.1 \pm 0.3$ & 0.397 \\
\hline$R V D 2 \mathrm{~cm}$ & $3.3 \pm 0.6$ & $3.5 \pm 0.4$ & $3.4 \pm 0.5$ & 0.581 \\
\hline$R V D 3 \mathrm{~cm}$ & $4.5 \pm 0.2$ & $4.6 \pm 0.5$ & $4.6 \pm 0.4$ & 0.749 \\
\hline$R V E D A \mathrm{~cm}^{2}$ & $13.9 \pm 1.6$ & $15.2 \pm 1.1$ & $14.6 \pm 1.4$ & 0.183 \\
\hline \multirow[t]{2}{*}{ LVEDV $m L$} & $81.0 \pm 4.9$ & $76.6 \pm 7.5$ & $78.8 \pm 6.4$ & 0.306 \\
\hline & \multicolumn{4}{|c|}{ 30min. post-ROSC } \\
\hline$R V D 1 \mathrm{~cm}$ & $3.7 \pm 0.3$ & $3.6 \pm 0.4$ & $3.7 \pm 0.3$ & 0.582 \\
\hline$R V D 2 \mathrm{~cm}$ & $3.0 \pm 0.4$ & $2.9 \pm 0.4$ & $2.9 \pm 0.4$ & 0.716 \\
\hline
\end{tabular}




\begin{tabular}{|c|c|c|c|c|}
\hline$R V D 3 \mathrm{~cm}$ & $4.5 \pm 0.2$ & $4.6 \pm 0.1$ & $4.5 \pm 0.2$ & 0.776 \\
\hline$R V-F A C \%$ & $27.4 \pm 2.8$ & $32.0 \pm 9.3$ & $30.5 \pm 6.5$ & 0.494 \\
\hline LVEDV $m L$ & $77.0 \pm 6.5$ & $73.8 \pm 9.7$ & $75.4 \pm 8.0$ & 0.558 \\
\hline LVESV $m L$ & $35.8 \pm 5.1$ & $35.4 \pm 3.7$ & $35.6 \pm 4.2$ & 0.897 \\
\hline LVEF \% & $47.6 \pm 5.0$ & $42.0 \pm 8.1$ & $44.8 \pm 7.0$ & 0.225 \\
\hline$L V-G L S \%$ & $-11.6 \pm 3.3$ & $-13.2 \pm 4.7$ & $-12.4 \pm 3.9$ & 0.548 \\
\hline$L V-G W I m m H g \%$ & $891.2 \pm 412.7$ & $1201.8 \pm 400.5$ & $1046.5 \pm 416.8$ & 0.262 \\
\hline$\angle V-G C W m m H g \%$ & $719.0 \pm 497.8$ & $919.6 \pm 638.2$ & $819.3 \pm 549.8$ & 0.595 \\
\hline$L V-G W W m m H g \%$ & $360.4 \pm 271.1$ & $240.2 \pm 148.1$ & $300.3 \pm 215.4$ & 0.416 \\
\hline$\angle V-G W E \%$ & $63.4 \pm 7.7$ & $75.0 \pm 8.7$ & $69.2 \pm 9.9$ & 0.256 \\
\hline TASV cm/sec. & $10.4 \pm 4.9$ & $9.8 \pm 1.8$ & $10.1 \pm 3.5$ & 0.803 \\
\hline$R V-G L S \%$ & $-6.6 \pm 3.3$ & $-9.4 \pm 2.9$ & $-8.0 \pm 3.3$ & 0.193 \\
\hline RV-GWI mmHg\% & $101.6 \pm 34.5$ & $92.0 \pm 33.3$ & $96.8 \pm 32.4$ & 0.666 \\
\hline$R V-G C W m m H g \%$ & $152.2 \pm 15.5$ & $159.6 \pm 20.2$ & $164.1 \pm 40.0$ & 0.395 \\
\hline$R V-G W W m m H g \%$ & $59.4 \pm 11.9$ & $49.4 \pm 9.1$ & $52.3 \pm 13.2$ & 0.843 \\
\hline \multirow[t]{2}{*}{$R V-G W E \%$} & $70.6 \pm 12.0$ & $74.0 \pm 8.6$ & $72.3 \pm 10.0$ & 0.621 \\
\hline & 3h. post-ROSC & & & \\
\hline$R V D 1 \mathrm{~cm}$ & $3.3 \pm 0.3$ & $3.4 \pm 0.3$ & $3.4 \pm 0.3$ & 0.782 \\
\hline$R V D 2 \mathrm{~cm}$ & $2.7 \pm 0.3$ & $2.8 \pm 0.1$ & $2.8 \pm 0.2$ & 0.347 \\
\hline$R V D 3 \mathrm{~cm}$ & $4.4 \pm 0.1$ & $4.3 \pm 0.3$ & $4.3 \pm 0.2$ & 0.718 \\
\hline$R V-F A C \%$ & $32.5 \pm 5.0$ & $43.3 \pm 7.0$ & $43.2 \pm 6.8$ & 0.945 \\
\hline$\angle V E D V m L$ & $78.2 \pm 1.1$ & $70.8 \pm 1.3$ & $74.5 \pm 4.1$ & $<0.001$ \\
\hline LVESV $m L$ & $38.0 \pm 4.9$ & $35.2 \pm 3.5$ & $36.6 \pm 4.3$ & 0.342 \\
\hline LVEF \% & $61.5 \pm 5.8$ & $64.7 \pm 9.2$ & $63.1 \pm 7.5$ & 0.525 \\
\hline$L V-G L S \%$ & $-12.2 \pm 2.8$ & $-16.0 \pm 2.3$ & $-14.1 \pm 3.1$ & 0.058 \\
\hline LV-GWI mmHg\% & $896.2 \pm 129.3$ & $1399.2 \pm 347.3$ & $1147.7 \pm 362.4$ & 0.116 \\
\hline LV-GCW mmHg\% & $719.0 \pm 497.8$ & $1598.8 \pm 849.2$ & $1158.9 \pm 803.5$ & 0.081 \\
\hline$L V-G W W m m H g \%$ & $264.6 \pm 78.9$ & $293.4 \pm 212.5$ & $279.0 \pm 151.9$ & 0.784 \\
\hline LV-GWE \% & $67.2 \pm 3.3$ & $81.4 \pm 5.6$ & $74.3 \pm 8.7$ & 0.010 \\
\hline
\end{tabular}




\begin{tabular}{|c|c|c|c|c|}
\hline$T A S V \mathrm{~cm} / \mathrm{sec}$. & $7.8 \pm 1.6$ & $11.4 \pm 1.1$ & $11.0 \pm 1.5$ & 0.024 \\
\hline$R V-G L S \%$ & $-10.0 \pm 1.0$ & $-12.0 \pm 2.7$ & $-11.0 \pm 2.2$ & 0.164 \\
\hline$R V-G W I m m H g \%$ & $108.4 \pm 22.6$ & $189.6 \pm 43.6$ & $149.0 \pm 53.9$ & 0.049 \\
\hline$R V-G C W m m H g \%$ & $203.4 \pm 39.6$ & $221.2 \pm 85.6$ & $212.3 \pm 63.6$ & 0.684 \\
\hline$R V-G W W m m H g \%$ & $69.6 \pm 11.9$ & $47.4 \pm 6.7$ & $47.8 \pm 13.3$ & 0.049 \\
\hline \multirow[t]{2}{*}{ RV-GWE \% } & $72.2 \pm 14.0$ & $75.0 \pm 11.1$ & $73.6 \pm 12.0$ & 0.734 \\
\hline & 5h post-ROSC & & & \\
\hline$R V D 1 \mathrm{~cm}$ & $3.5 \pm 0.5$ & $3.9 \pm 0.7$ & $3.7 \pm 0.6$ & 0.308 \\
\hline$R V D 2 \mathrm{~cm}$ & $2.8 \pm 0.4$ & $3.2 \pm 0.7$ & $3.0 \pm 0.6$ & 0.287 \\
\hline$R V D 3 \mathrm{~cm}$ & $4.4 \pm 0.2$ & $4.6 \pm 0.1$ & $4.5 \pm 0.2$ & 0.024 \\
\hline$R V-F A C \%$ & $33.2 \pm 4.3$ & $41.1 \pm 6.5$ & $37.1 \pm 6.7$ & 0.053 \\
\hline$\angle V E D V m L$ & $70.8 \pm 1.3$ & $68.2 \pm 2.7$ & $69.5 \pm 2.4$ & 0.087 \\
\hline LVESV $m L$ & $38.0 \pm 6.9$ & $35.6 \pm 4.5$ & $36.8 \pm 5.6$ & 0.525 \\
\hline LVEF \% & $51.4 \pm 3.0$ & $57.0 \pm 6.2$ & $54.2 \pm 5.5$ & 0.108 \\
\hline$L V-G L S \%$ & $-13.0 \pm 2.4$ & $-18.2 \pm 3.4$ & $-15.6 \pm 3.9$ & 0.036 \\
\hline$L V-G W I m m H g \%$ & $1125 \pm 214$ & $1529.2 \pm 274.5$ & $1251.3 \pm 348.4$ & 0.052 \\
\hline LV-GCW mmHg\% & $1203.8 \pm 253.0$ & $1728.4 \pm 466.7$ & $1466.1 \pm 449.1$ & 0.058 \\
\hline LV-GWW mmHg\% & $395.4 \pm 159.4$ & $367.0 \pm 87.2$ & $381.2 \pm 122.1$ & 0.736 \\
\hline$L V-G W E \%$ & $75.8 \pm 2.3$ & $82.6 \pm 4.0$ & $79.2 \pm 4.7$ & 0.071 \\
\hline$T A S V \mathrm{~cm} / \mathrm{s}$ & $9.4 \pm 1.3$ & $12.8 \pm 1.1$ & $9.9 \pm 2.2$ & 0.012 \\
\hline$R V-G L S \%$ & $-9.0 \pm 1.4$ & $-13.2 \pm 2.2$ & $-11.1 \pm 2.8$ & 0.040 \\
\hline$R V-G W I m m H g \%$ & $152.6 \pm 42.4$ & $261.6 \pm 54.2$ & $207.1 \pm 73.5$ & 0.041 \\
\hline RV-GCW mmHg\% & $224.4 \pm 158.7$ & $212.6 \pm 53.8$ & $218.5 \pm 111.9$ & 0.879 \\
\hline$R V-G W W m m H g \%$ & $77.8 \pm 14.8$ & $50.2 \pm 8.2$ & $61.4 \pm 22.4$ & 0.046 \\
\hline$R V$-GWE \% & $68 \pm 5.7$ & $80 \pm 5.2$ & $76 \pm 5.4$ & 0.042 \\
\hline
\end{tabular}

GCW: Global constructed myocardial work; GLS: Global longitudinal strain; GWE: Global myocardial work efficiency; GWI: Global myocardial work index; GWW: Global wasted work; LV: Left ventricle; LVEDV: Left ventricle end-diastolic volume; LVEF: Left ventricular ejection fraction; LVESV: Left ventricular end-systolic volume; RVEDA: right ventricle end-diastolic area ; RVD1: right ventricle basal diameter from apical 4 chamber view; RVD2: right ventricular mid diameter at midlevel from apical 4 chamber view; RVD3: right 
ventricle longitudinal diameter; RV-FAC: right ventricular fractional area change; TASV: TASV: Tricuspid annular systolic velocity

\section{Figures}
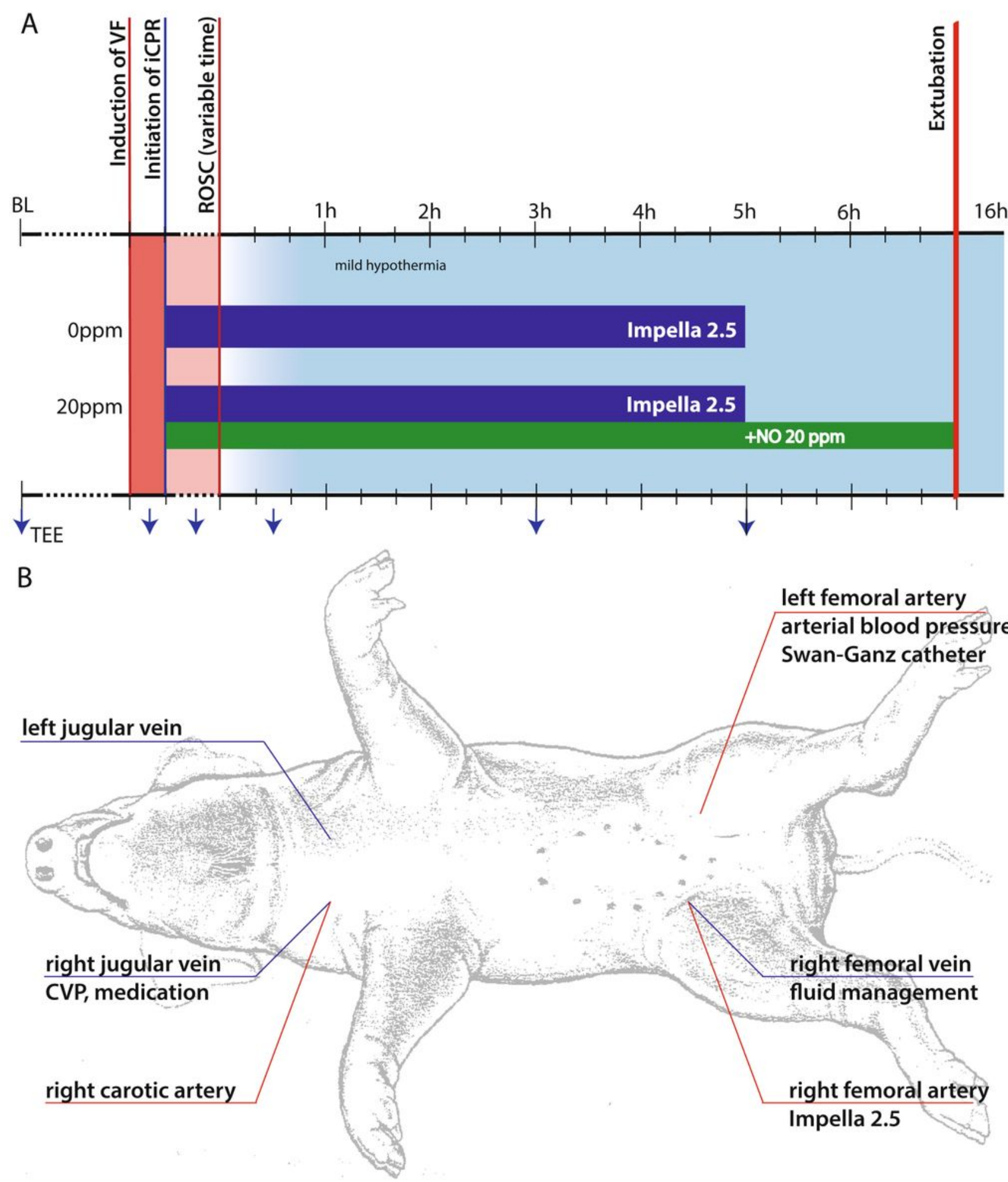

Figure 1 
Experimental model (A) and instrumentation (B) CVP: central venous pressure; iCPR: Percutaneous mechanical cardiopulmonary resuscitation; VF: ventricular fibrillation; ROSC: Return of spontaneous circulation
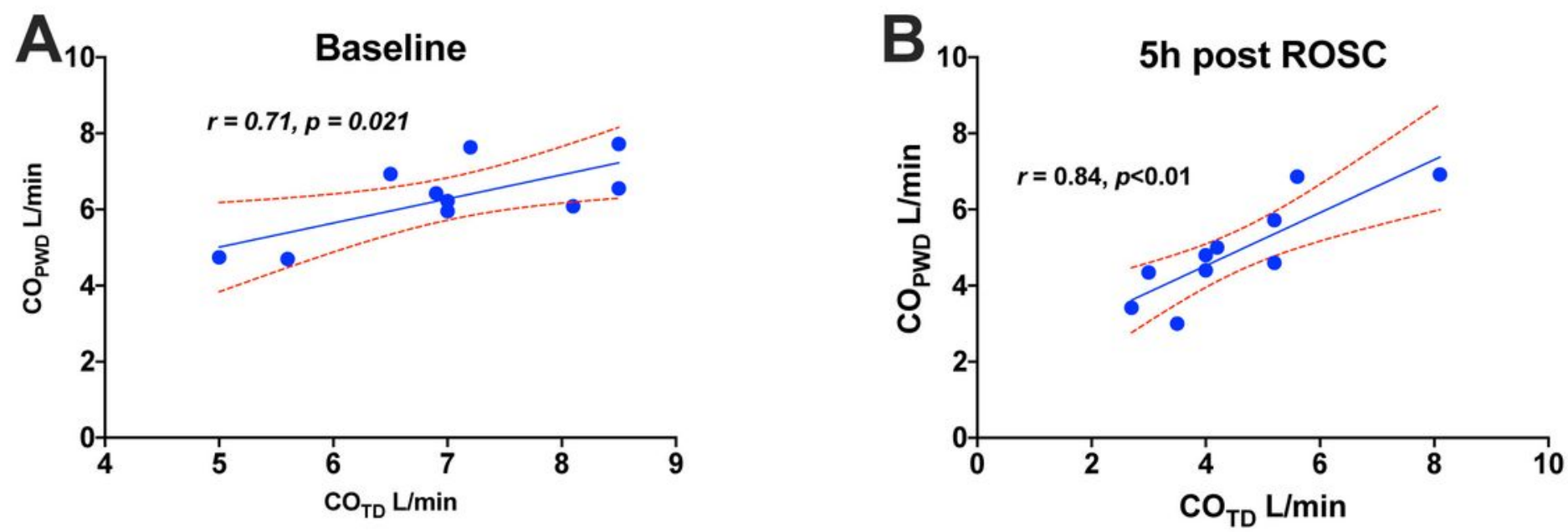

C
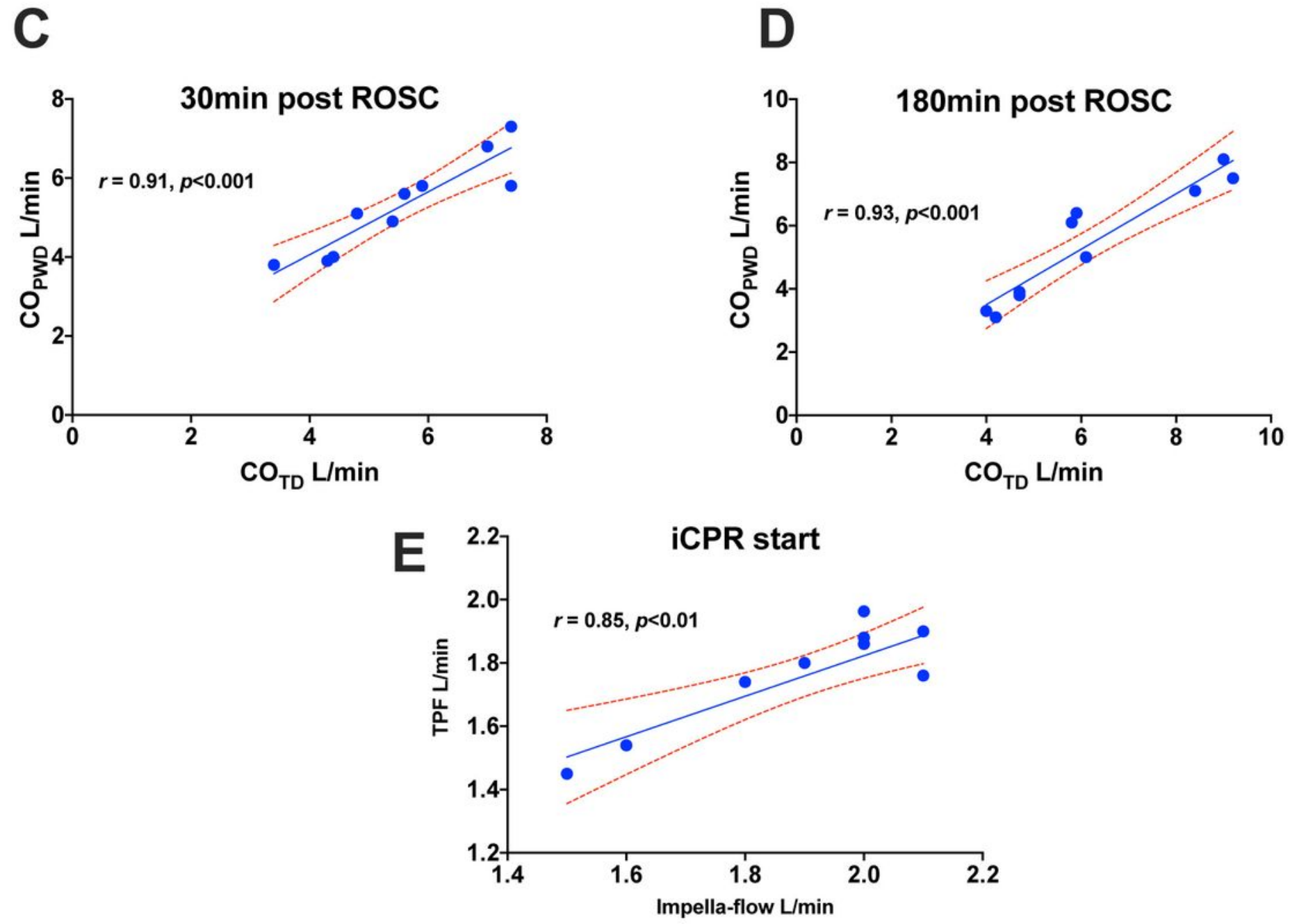

Figure 2

Cardiac output correlation between different methods of measurement. Comparison between cardiac output derived from pulsed-wave Doppler vs. thermodilution at different time-points (A, B, C, D) or vs. 
Impella flow as shown on the automated Impella Controller during iCPR (E) in all animals (not separated by treatment group). Shown are the individual comparisons, linear correlation within a $95 \%$ confidence interval (red dotted line).
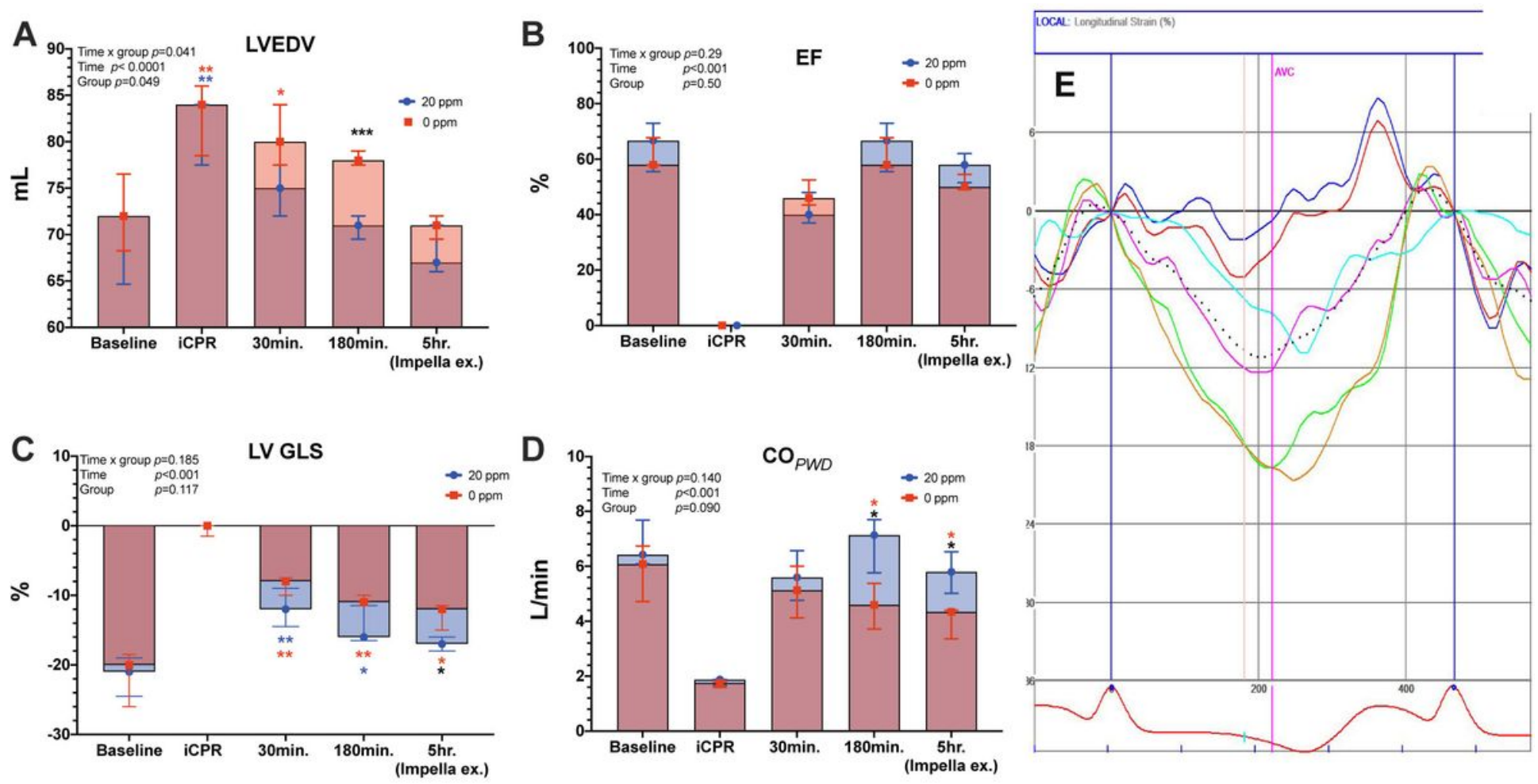

Figure 3

Time-course of left ventricular 2-dimensional echocardiographic parameters. A: Left ventricular enddiastolic volume (LVEDV); B: Left ventricular ejection fraction (EF); C: Left ventricular global longitudinal strain (LV GLS); D: Cardiac output as measured by pulsed-wave Doppler (COpwd); E: example of regional longitudinal strain analysis of the left ventricle. $*$ : $p<0.05 ; * \star$ : $p<0.01 ; * \star *$ : $p<0.001$. red asterisk: $0 p p m$ group compared to baseline; blue asterisk: 20ppm group compared to baseline; black asterisk: between groups at specific time-point. 
A

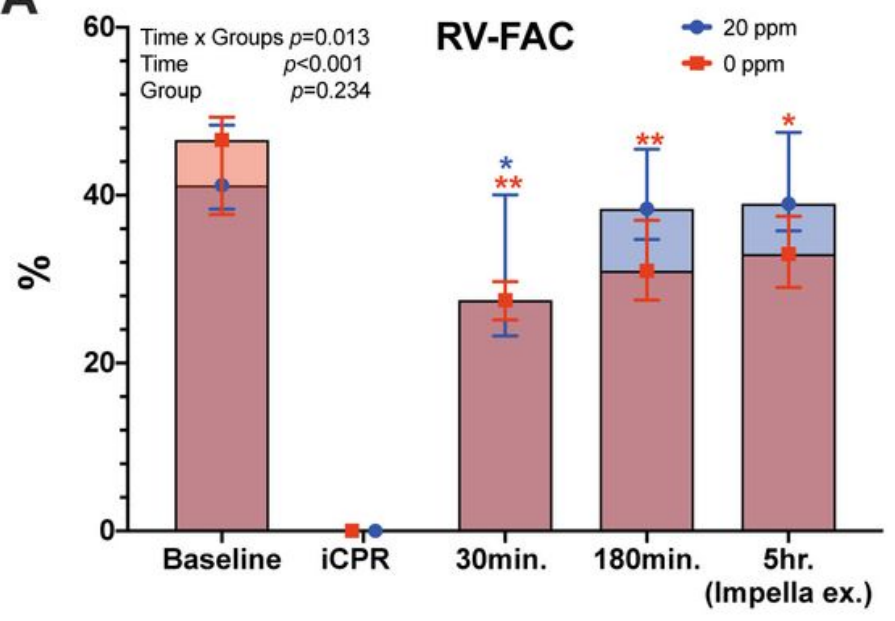

C

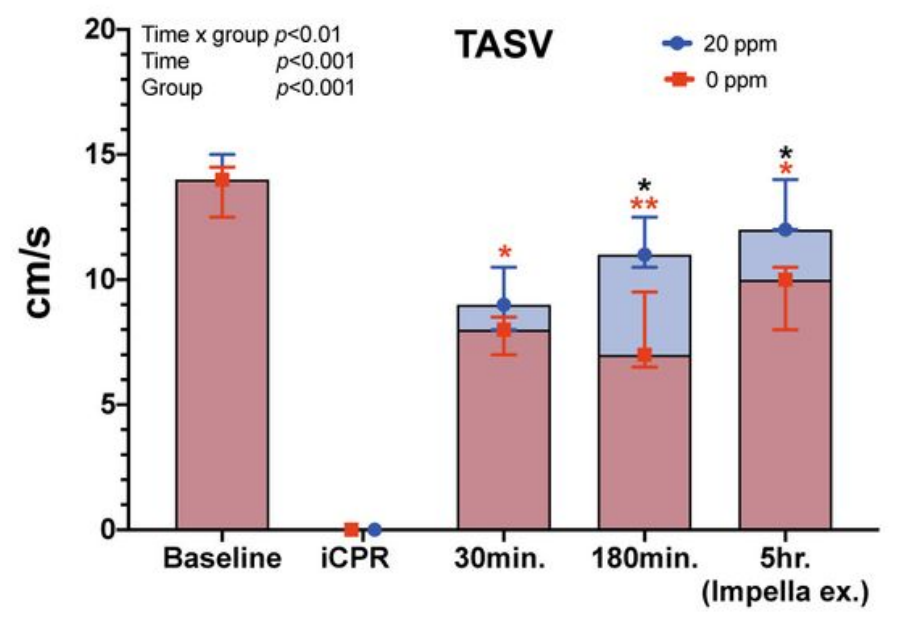

B

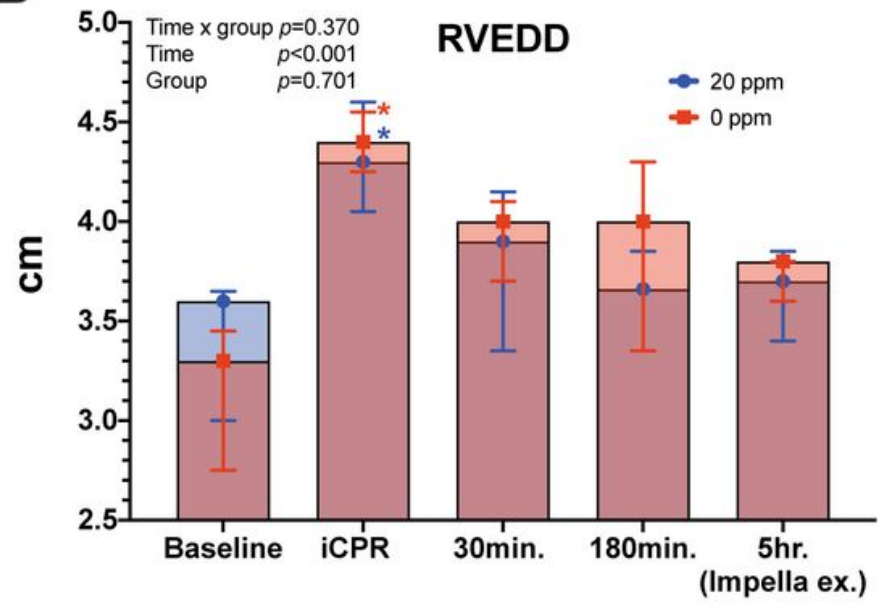

D

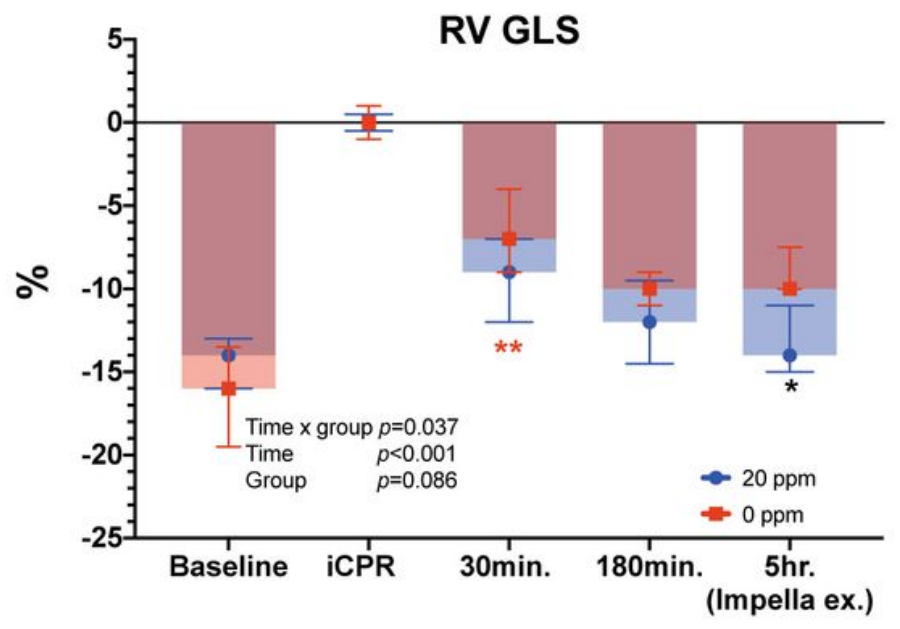

Figure 4

Time-course of right ventricular 2-dimensional echocardiographic parameters. A: Right ventricular fractional area change (RV-FAC); B: right ventricular end-diastolic diameter (RVEDD); C: tricuspid annular systolic velocity (TASV); D: right ventricular global longitudinal strain (RV GLS). *: $p<0.05$; **: $p<0.01$. Red asterisk: 0ppm group compared to baseline; blue asterisk: 20ppm group compared to baseline; black asterisk: between groups at specific time-point. 

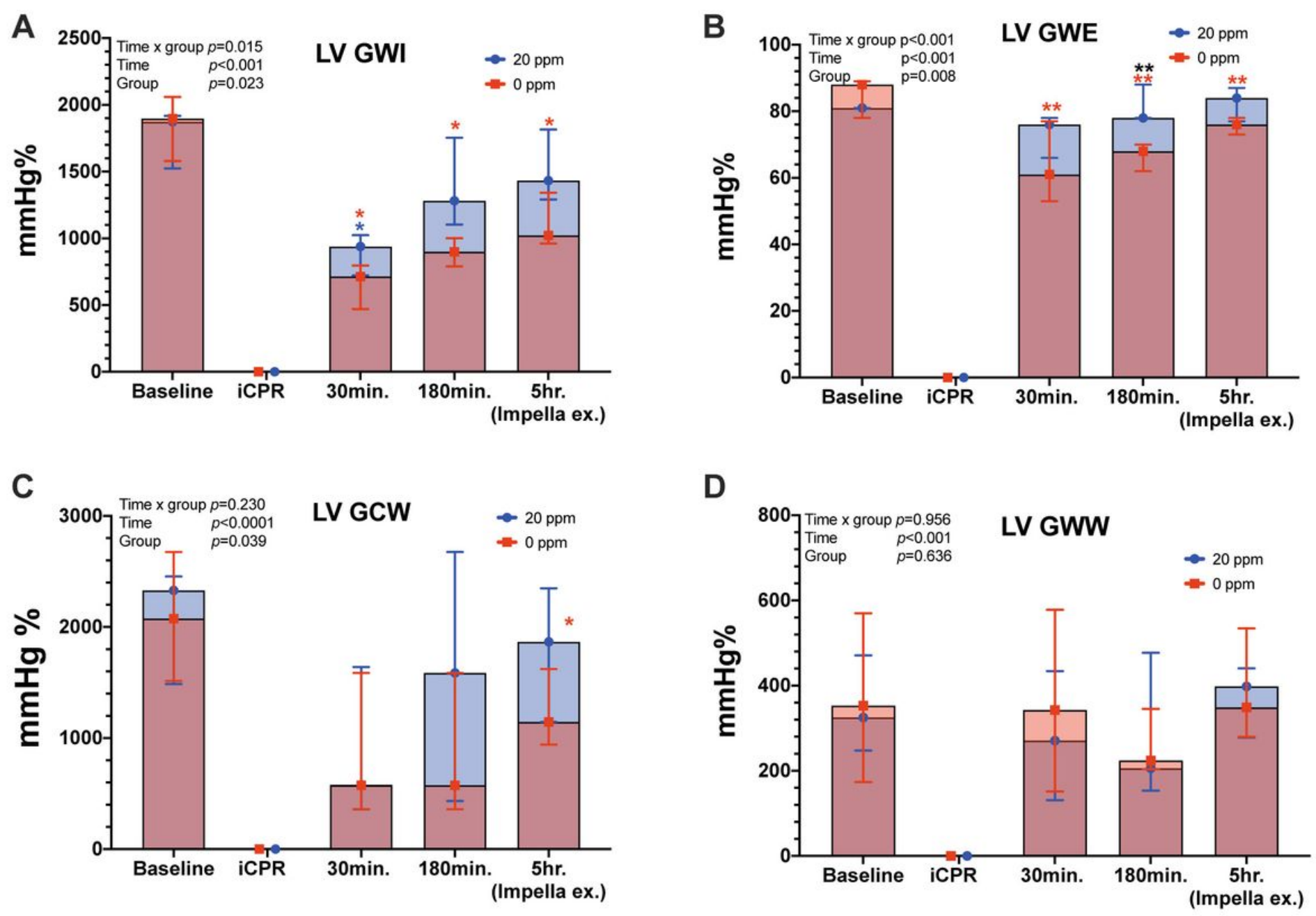

Figure 5

Changes of left ventricular function and myocardial work. A: Left ventricular global work index (LV GWI); B: Left ventricular global work efficiency (LV GWE); C: Left ventricular global constructed work (LV GCW); D: Left ventricular global wasted work (LV GWW). *: $p<0.05 ; \star \star *: p<0.01$. Red asterisk: Oppm group compared to baseline; blue asterisk: 20ppm group compared to baseline; black asterisk: between groups at specific time-point. 

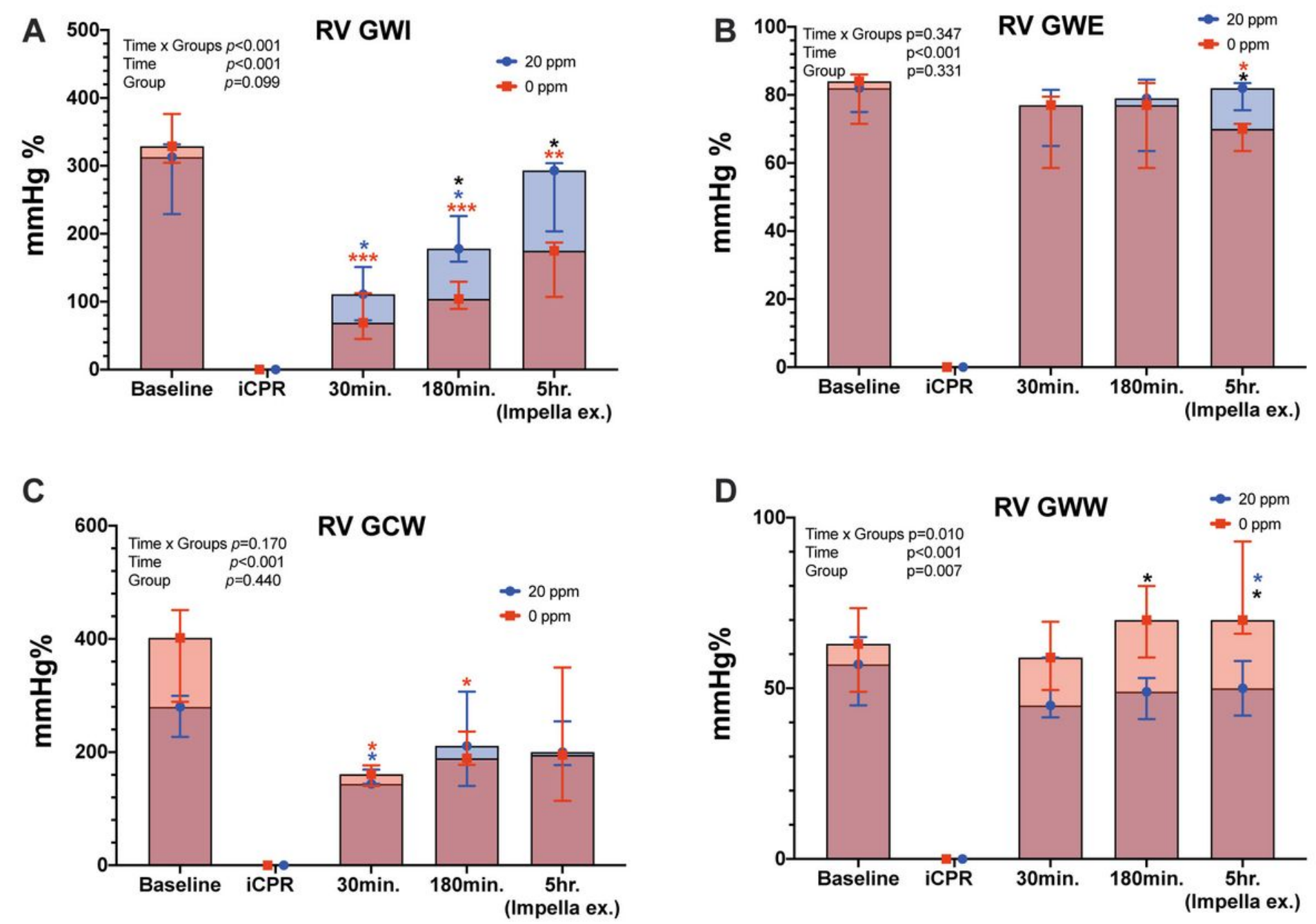

\section{Figure 6}

Changes of right ventricular function and myocardial work. A: Right ventricular global work index (RV GWI); B: Right ventricular global work efficiency (RV GWE); C: Right ventricular global constructed work (RV GCW); D: Right ventricular global wasted work (RV GWW). *: $p<0.05 ; \star \star *: p<0.01 ; * \star \star: p<0.001$. red asterisk: 0ppm group compared to baseline; blue asterisk: 20ppm group compared to baseline; black asterisk: between groups at specific time-point. 
A

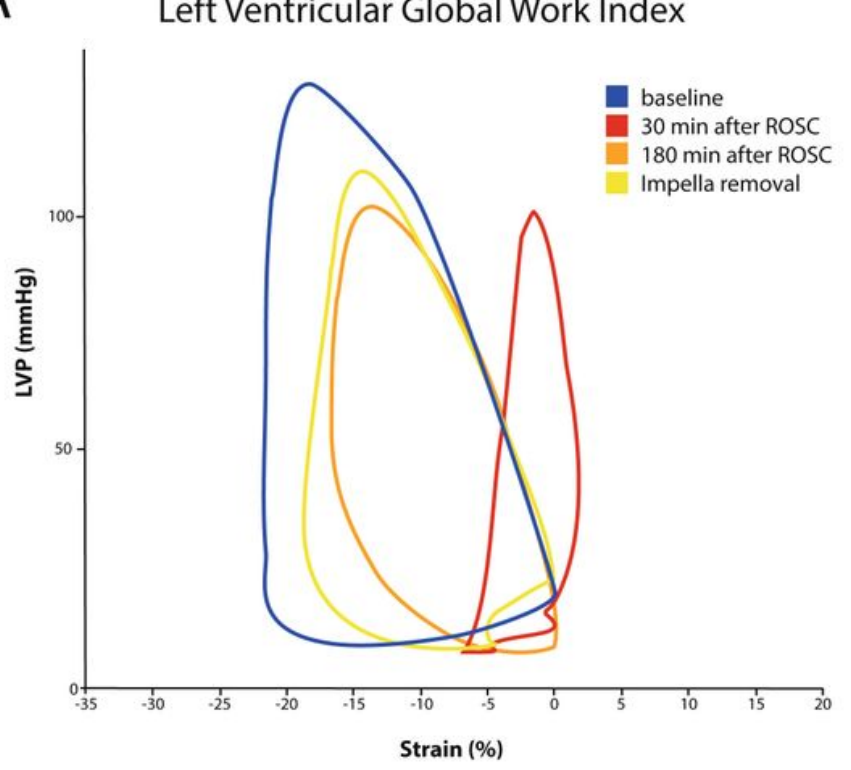

B

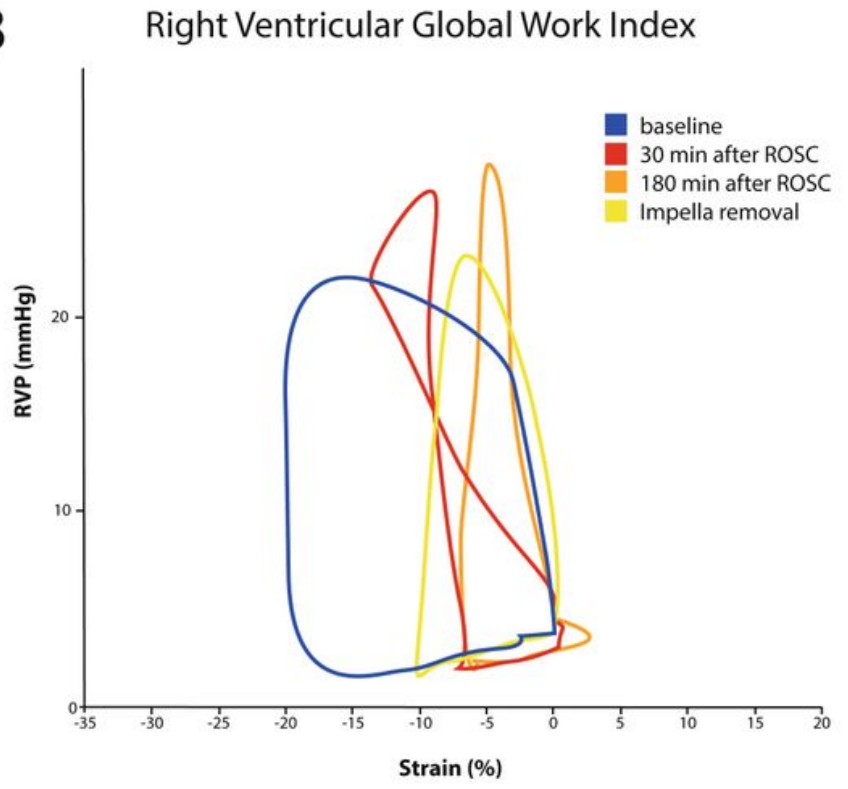

C

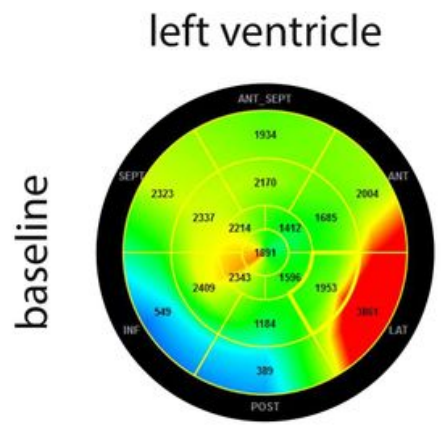

right ventricle
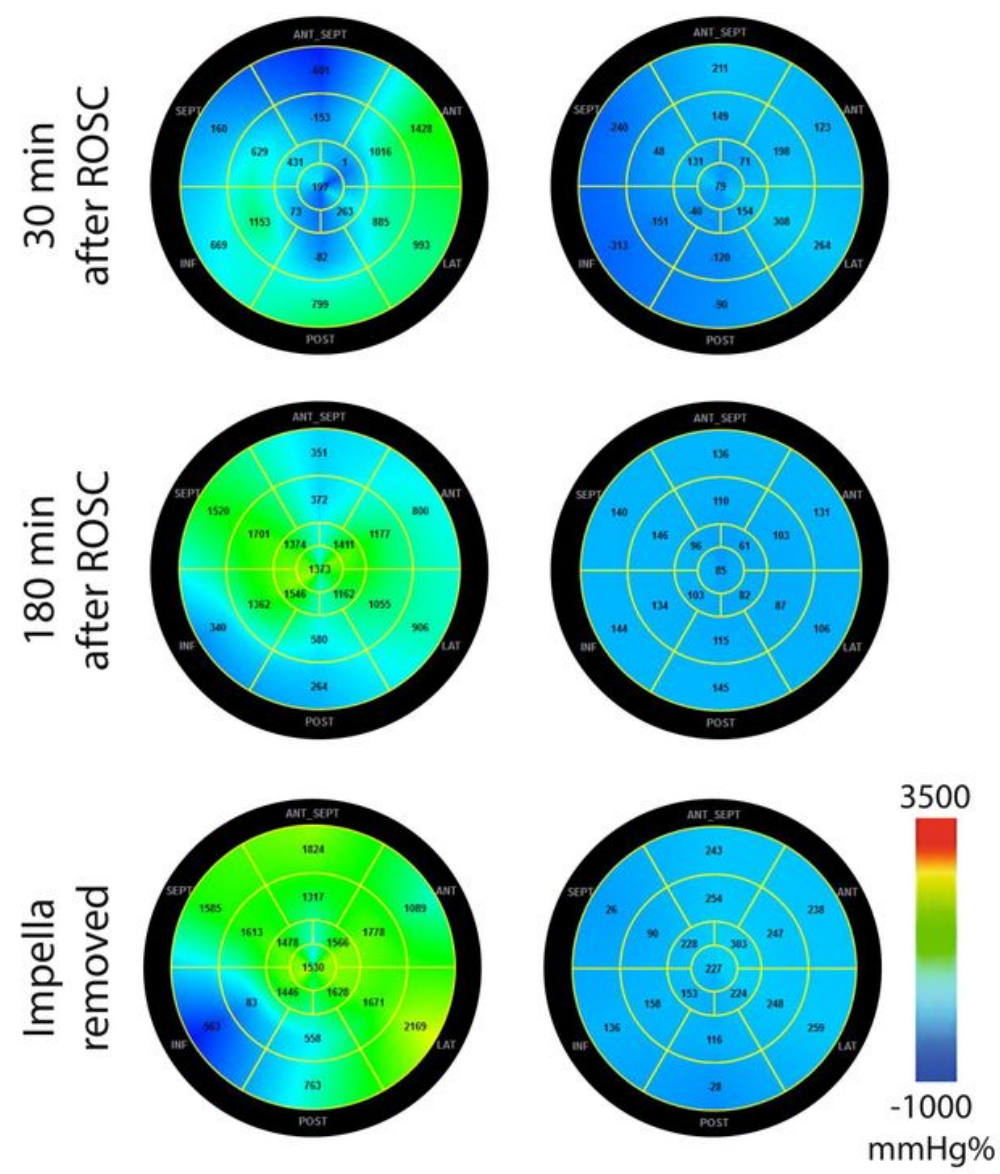

\section{Figure 7}

Exemplary demonstration of global myocardial work index changes during the experiment. A, B: relation of left/right ventricular pressure to global left/right ventricular strain over time. Comparable to a PV-loop, this allows to gain insights on myocardial workload and function. C: example of spatial distribution of right and left ventricular myocardial work index. Myocardial work indices are color coded from red to blue, where red color indicate the maximum value and blue the lowest myocardial work index value.

\section{Supplementary Files}

This is a list of supplementary files associated with this preprint. Click to download. 
- GraphicalAbstract.pdf

Page 29/29 